\author{
UNIVERSIDADE DE SÃO PAULO \\ FACULDADE DE ECONOMIA, ADMINSTRAÇÃO E \\ CONTABILIDADE \\ PROGRAMA DE PÓS-GRADUAÇÃO EM ECONOMIA
}

PRÊMIOS REALIZADOS E ESPERADOS NO BRASIL

Michael Tulio Ramos de França

Orientador: Prof. Dr. Joe Akira Yoshino

São Paulo

2015 
Prof. Dr. Marco Antonio Zago

Reitor da Universidade de São Paulo

Prof. Dr. Adalberto Américo Fischmann

Diretor da Faculdade de Economia, Administração e Contabilidade

Prof. Dr. Hélio Nogueira da Cruz

Chefe do Departamento de Economia

Prof. Dr. Márcio Issao Nakane

Coordenador do Programa de Pós-Graduação em Economia 
Michael Tulio Ramos de França

\title{
PRÊMIOS REALIZADOS E ESPERADOS NO BRASIL
}

\begin{abstract}
Dissertação apresentada ao Programa de PósGraduação em Economia do Departamento de Economia da Faculdade de Economia, Administração e Contabilidade da Universidade de São Paulo, como requisito parcial para a obtenção do título de Mestre em Ciências.
\end{abstract}

Orientador: Prof. Dr. Joe Akira Yoshino

Versão Corrigida

(versão original disponível na Faculdade de Economia, Administração e Contabilidade)

São Paulo

2015 
Autorizo a reprodução e divulgação total ou parcial deste trabalho, por qualquer meio convencional ou eletrônico, para fins de estudo e pesquisa, desde que citada a fonte.

FICHA CATALOGRÁFICA

Elaborada pela Seção de Processamento Técnico do SBD/FEA/USP

França, Michael Tulio Ramos de

Prêmios realizados e esperados no Brasil / Michael Tulio Ramos de França. -- São Paulo, 2015.

$89 \mathrm{p}$.

Dissertação (Mestrado) - Universidade de São Paulo, 2015.

Orientador: Joe Akira Yoshino.

1. Finanças. 2. Retorno esperado. 3. Risco. 4. Inferência I. Universidade de São Paulo. Faculdade de Economia, Administração e Contabilidade. II. Título.

$\mathrm{CDD}-332$ 
Michael Tulio Ramos de França

Prêmios realizados e esperados no Brasil

Dissertação apresentada a Faculdade de Economia, Administração e Contabilidade da Universidade de São Paulo, para obtenção do título de Mestre em Economia.

Aprovado em:

Banca Examinadora

Professor Doutor Joe Akira Yoshino

Faculdade de Economia e Administração da Universidade de São Paulo

Professor Doutor José Carlos de Souza Santos

Faculdade de Economia e Administração da Universidade de São Paulo

Professor Doutor Marcelo Bianconi

Tufts University 
Aos meus pais, Espedito e Zila, por todo carinho e por terem sido os melhores pais que um filho poderia ter. 


\section{AGRADECIMENTOS}

Primeiramente, gostaria de agradecer aos meus pais. Dado suas origens socioeconômicas, acho que eles nunca entenderam o que é um economista e porque estudo tanto. Apesar disso, sempre foram muito afetuosos comigo.

Ao meu irmão, Diego Kennedy, por ter mostrado o caminho.

À Faculdade de Economia e Administração da Universidade de São Paulo pela oportunidade que tive de conhecer pessoas sensacionais. Em termos de desenvolvimento pessoal, posso afirmar com toda convicção que foi o período mais proveitoso da minha vida.

Aos meus professores do mestrado por todo o conhecimento compartilhado.

Um agradecimento especial aos professores Bruno Giovannetti, Fernando Chague e Rodrigo de Losso pela ajuda inicial. Além desses, tenho um forte sentimento de gratidão a dois professores em particular. Primeiro, ao meu orientador Joe Yoshino, pelo amparo e por ter me dado todo auxílio que precisei. Segundo, ao professor Marcelo Bianconi, suas sugestões sobre a pesquisa foram de extrema importância para conclusão do trabalho.

Ao professor David Turchick por toda ajuda, conselhos, conversas e por ter sido um dos melhores professores que já tive.

À professora Paula Pereda por me convidar para representar a USP em Amsterdam no $16^{\circ}$ Econometric Game (World Championship of Econometrics).

À professora Marilda Sotomayor pela experiência do congresso de teorias dos jogos (Game Theory and Economic Applications of the Game Theory Society) e pelo fato de ser uma pessoa fantástica.

Ao coordenador do curso de pós-graduação em Ciências Econômicas.

Aos examinadores da banca de defesa pela participação.

Enfim, agradeço a todos aqueles que tive a oportunidade de compartilhar algo. Como bem destacou Gonzaguinha: "Toda pessoa sempre é as marcas das lições diárias de outras tantas pessoas. E é tão bonito quando a gente entende que a gente é tanta gente onde quer que a gente vá". 
“É possível que você nunca consiga, por exemplo, prever o que qualquer pessoa fará, mas pode dizer com precisão o que caberá, a um número médio de pessoas, fazer. Os indivíduos variam, mas as porcentagens permanecem constantes. Assim falam os estatísticos" 


\section{RESUMO}

Dado que o investimento no mercado acionário envolve incerteza, devíamos esperar que seu retorno médio fosse relativamente superior a uma aplicação livre de risco para compensar o investidor pelo risco adicional que ele incorre quando aplica seus recursos em ações. Entretanto, não encontramos tal evidência quando analisamos o comportamento do mercado acionário brasileiro. Isto porque, considerando os retornos realizados médio dos últimos vinte anos, o prêmio histórico foi relativamente baixo. Assim, naturalmente surge à questão se tal estimativa corresponde a um valor razoável para inferirmos o futuro comportamento do mercado acionário. Para responder a esta questão, nossa metodologia constituiu em três etapas. Na primeira, revisamos a literatura em busca de técnicas de estimação do prêmio e selecionamos as abordagens baseado em artigos recentes, citações e disponibilidade de dados. Além disso, também realizamos algumas propostas de estimação. Em seguida, apresentamos os resultados das metodologias selecionadas para os anos recentes e observamos que as estimativas apresentaram certo grau de heterogeneidade. Na segunda etapa, testamos 0 desempenho dos modelos empíricos estimados usando testes de previsão fora da amostra. Os resultados apontaram que alguns modelos foram superiores ao prêmio histórico. Desta forma, encontramos evidências de que o prêmio histórico representa apenas mais uma fonte de informação para inferir o prêmio esperado e, se tomado sozinho, não constitui um procedimento de inferência razoável. Visto que cada modelo apresenta uma estratégia empírica para inferir o prêmio, todos deveriam representar uma fonte informacional sobre o prêmio futuro. Consequentemente, uma corrente da literatura recente destaca que a estratégia ótima pode ser agregar informações dos modelos individuais. Com este intuito, o último passo da metodologia foi combinar informações dos modelos que apresentaram melhor desempenho em relação ao prêmio histórico e verificar se tal procedimento aumentou a performance do poder preditivo dos modelos. Como resultado, verificamos que tal abordagem melhora e estabiliza a previsão do prêmio.

Palavras-chave: Finanças. Retorno esperado. Risco. Inferência. 


\begin{abstract}
Given that investment in the stock market involves uncertainty, we should expect that the average return was relatively higher than a risk-free investment in order to compensate investors for the additional risk they incur. However, we find no such evidence when we analyze the Brazilian stock market behavior. This is because, considering the realized average returns of the past twenty years, the historic equity risk premium was relatively low. So, naturally, the question of whether such an estimate corresponds to a reasonable value to infer the future behavior of the stock market arises. To answer this question, our methodology consists of three stages. At first, we review the literature on risk premium estimation techniques and select the different approaches based on recent articles, quotes and availability of data. We also made some estimation proposals. We then proceed and present the results of the methodologies selected for the recent years and find that the estimates presented some degree of heterogeneity. On the second step, we test the performance of our estimates using out-of-sample predictive tests. The results showed that some models performed better than the historical premium. Thus, we find evidence that the historical premium is just another source of information to infer the expected award and, if taken alone, does not constitute a reasonable inference procedure. Since each model presents an empirical strategy to infer the premium, every one of them should represent an information source on the future premium. Consequently, a recent literature points out that the current optimal strategy may be to aggregate information from individual models. To this end, the last step of the methodology was to combine information of the models that performed better against the historical premium and verify that this procedure increased the power of the predictive performance of the models. As a result, we find that this approach improves and stabilizes the premium forecast.
\end{abstract}

Keywords: Finance. Expected return. Risk. Inference 


\section{ÍNDICE DE GRÁFICOS}

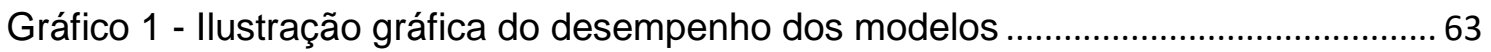

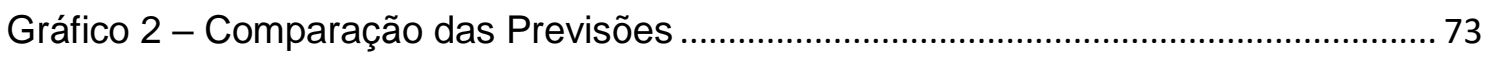




\section{ÍNDICE DE TABELAS}

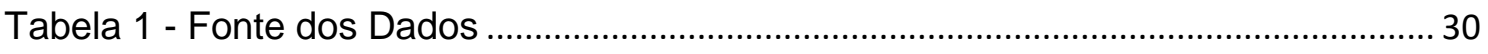

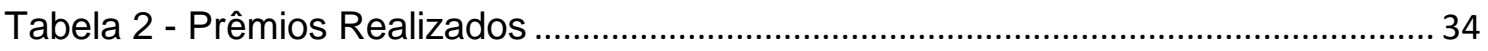

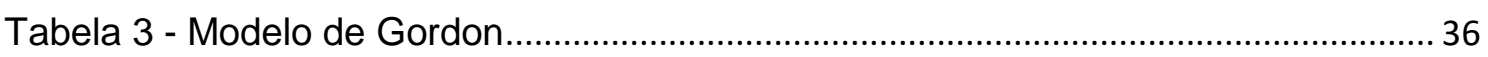

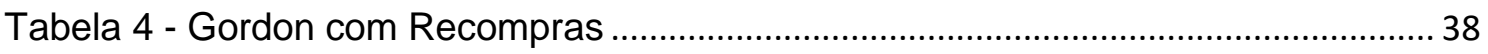

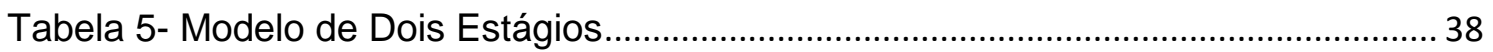

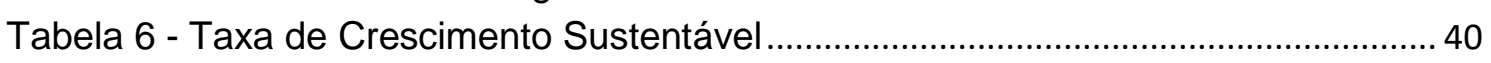

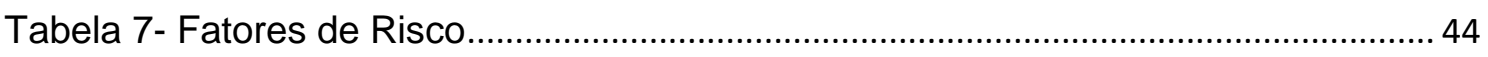

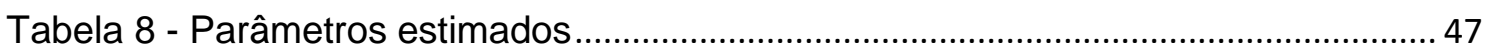

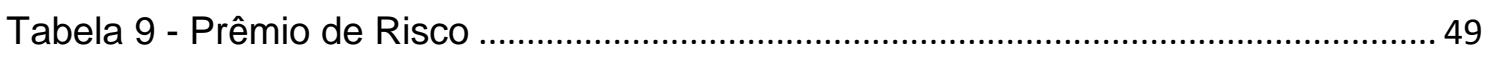

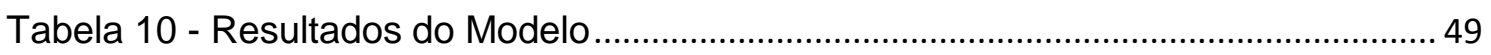

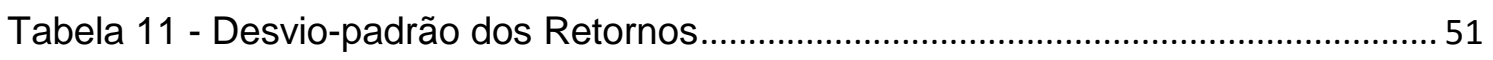

Tabela 12 - ERP e Prêmio de Risco do País .......................................................................... 51

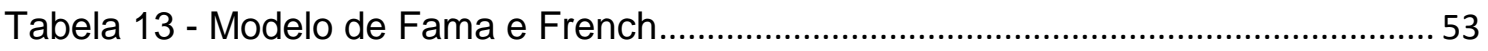

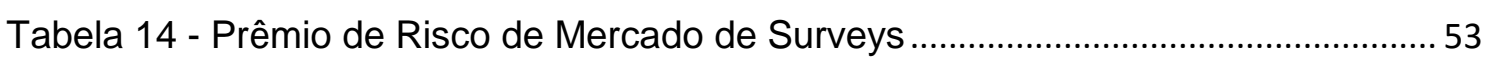

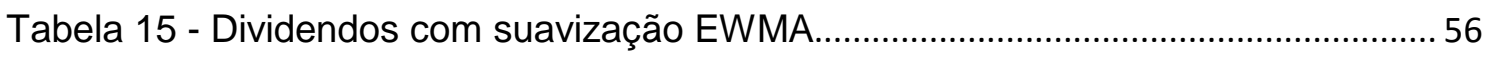

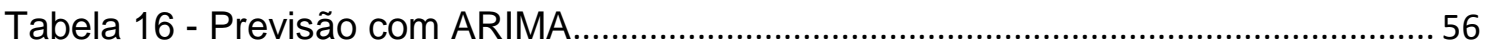

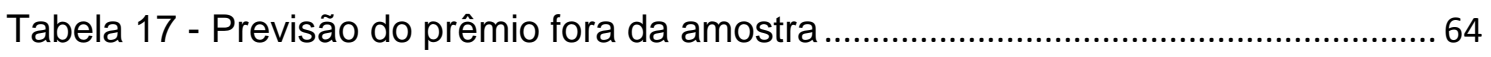

Tabela 18 - Teste para a previsibilidade de médio e longo prazo ..................................... 66

Tabela 19 - Testando o poder preditivo da média histórica de curto prazo ...................... 67

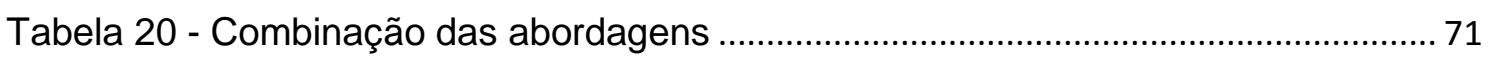

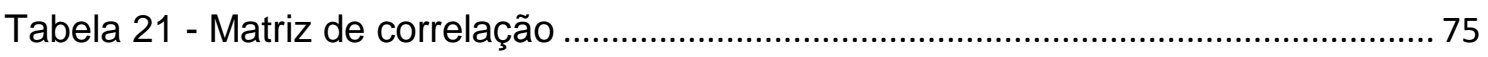

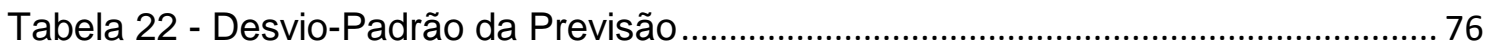




\section{SUMÁRIO}

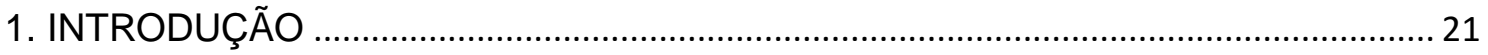

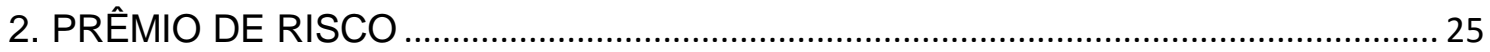

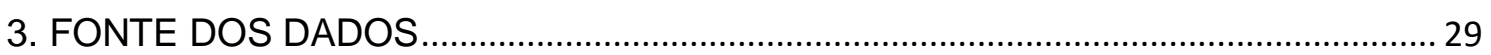

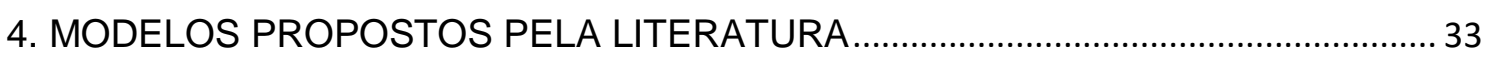

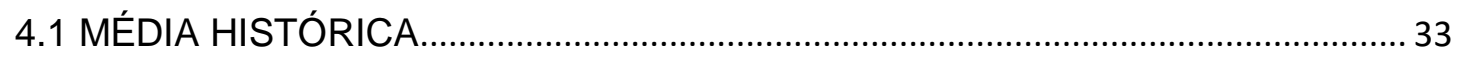

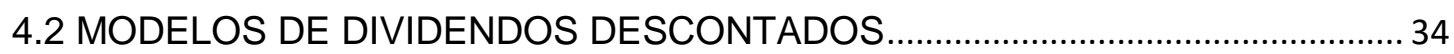

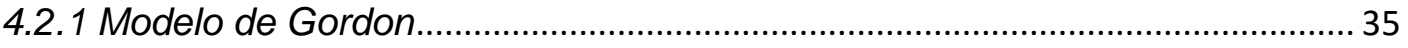

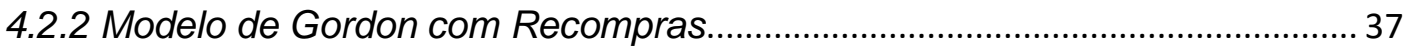

4.2.3 Modelo de Dois Estágios de Crescimento........................................................ 38

4.2.4 Modelo da Taxa de Crescimento Sustentável ................................................. 38

4.3 REGRESSÕES DE CROSS-SECTIONAL ............................................................. 40

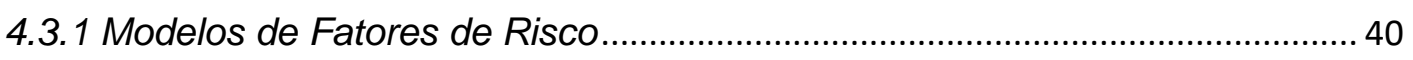

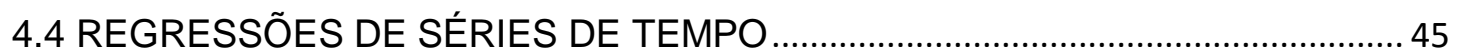

4.4.2 Estimação por Máxima Verossimilhança........................................................... 46

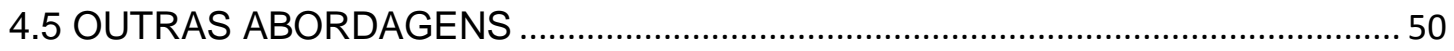

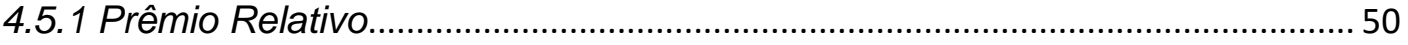

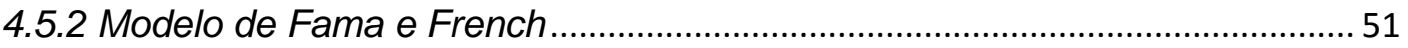

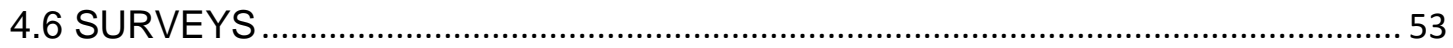

5. EXTENSÕES AOS MODELOS PROPOSTOS PELA LITERATURA ............................ 55

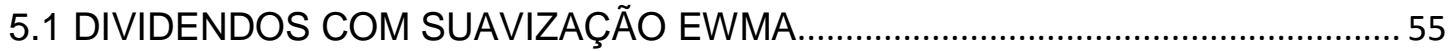

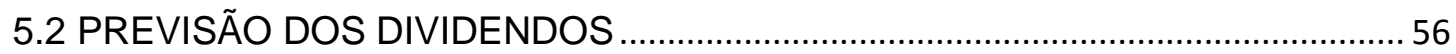

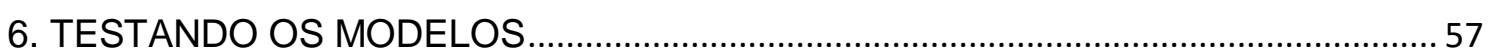

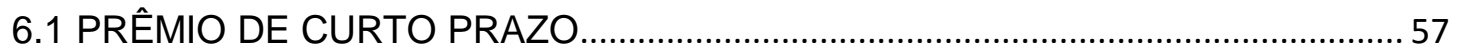

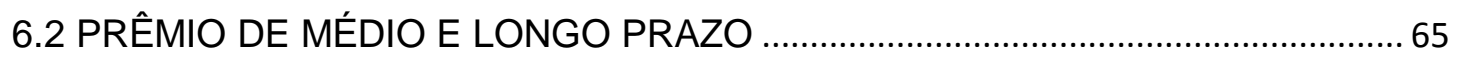

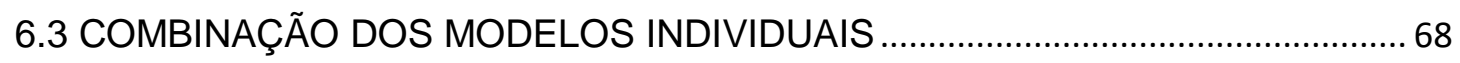

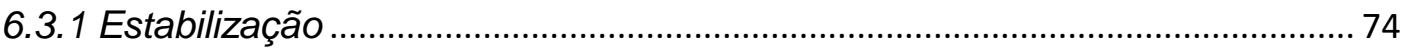

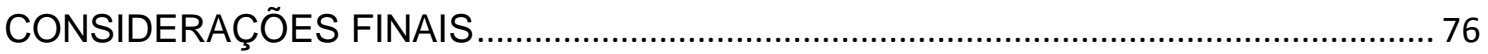

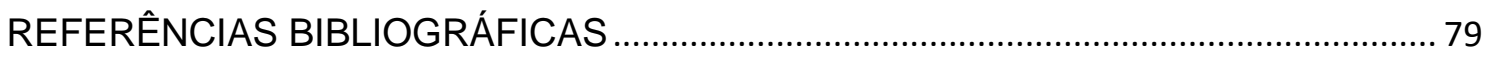

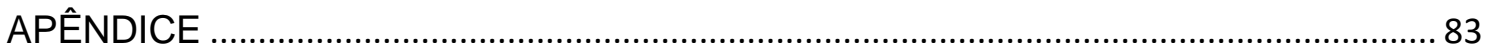




\section{INTRODUÇÃO}

Quando um investidor aplica seus recursos no mercado acionário, ele espera receber um retorno maior do que uma aplicação num ativo livre de risco. Isto ocorre devido ao fato do investimento no mercado acionário envolver incerteza e, portanto, deveria oferecer um retorno relativamente maior que um ativo livre de risco de tal forma que compensaria o risco assumido pelo investidor. Entretanto, não constatamos tal fato quando analisamos o desempenho do mercado acionário brasileiro dos últimos 20 anos. Isto porque, no período compreendido entre janeiro de 1995 a dezembro de 2014, a diferença entre o rendimento médio mensal do Ibovespa e da Selic foi de apenas $0.02 \%$. Consequentemente, de tal fato, emerge a questão se o prêmio histórico (também denominado como média histórica) corresponde a uma estimativa razoável para inferirmos o futuro comportamento do mercado acionário brasileiro.

Existe na literatura um prolífero debate em torno de qual é a metodologia mais adequada para estimar o prêmio de risco. No entanto, não há um consenso. Com o objetivo de facilitar e promover o debate acadêmico em torno desta questão incerta em finanças, Spiegel (2008) publicou um artigo procurando sintetizar a discussão sobre a estimação do prêmio de risco e apresentou um resumo de onde a pesquisa se encontra atualmente. Para isso, ele expôs os principais resultados de artigos que procuram responder a seguinte questão: Pode algum modelo empírico prever o prêmio de risco mais apuradamente que a prêmio histórico?

Nesse sentido, o artigo de Goyal e Welch (2008) apresentou evidências que a previsibilidade fora da amostra do prêmio histórico é melhor do que qualquer modelo empírico mais complexo. Este artigo casou muita polemica entre os pesquisadores do assunto, visto que uma grande quantidade de artigos vinham apresentando argumentos num sentido contrario. Assim, prontamente, surgiram vários autores que apresentaram posições diferentes. Campbell e Thompson (2008) argumentaram que modelos empíricos podem ser úteis na previsibilidade fora da amostra quando colocamos restrições sobre seus parâmetros de maneira economicamente justificada. Já Cochrane (2008) propôs um novo teste in-sample e 
destacou que ao contrário da simples visão de random walk, os retornos das ações parecem ser previsíveis ${ }^{1}$.

Entretanto, significância in-sample não garante previsibilidade out-sample (INOUE e KILLIAN, 2004). Assim, embora ainda não esteja claro na literatura qual peso deve ser dado a cada tipo de abordagem, é crescente o número de artigos que procuram usar a abordagem de previsibilidade out-sample para verificar quais modelos propostos teriam ajudado em tempo real os investidores em suas decisões de investimento (CAMPBELL e THOMPSON, 2008). Com este objetivo, Rapach, Strauss e Zhou (2010) documentaram que podemos melhorar o poder preditivo fora da amostra combinando informações das previsões individuais. $\mathrm{Li}, \quad \mathrm{Ng}$ e Swaminatahn (2013) elaboraram uma nova variável para calcular o prêmio de risco implícito e argumentaram que ela possui um significativo poder preditivo dentro e fora da amostra. Chin e Polk (2015) usam a metodologia do VAR para combinar informações de várias variáveis e demonstrar que o poder explicativo fora da amostra foi alto tanto para os Estados Unidos quanto para o Reino Unido.

Neste trabalho, nossa metodologia consistiu em três etapas. Na primeira, procuramos selecionar os principais modelos sugeridos pela literatura e, em seguida, também realizamos algumas propostas. Estimamos os modelos selecionados para os anos recentes e, ao final, montamos um painel com os resultados estimados. Na segunda etapa, testamos se os modelos estimados apresentaram um desempenho superior à média histórica no mercado acionário brasileiro. Além disso, também verificamos se a previsibilidade dos modelos altera quando consideramos o prêmio de médio e longo prazo. Como resultado, obtemos evidências que alguns modelos superam o poder preditivo da média histórica e que tal previsibilidade tende a aumentar no tempo. As estimativas do prêmio foram construídas no tempo real e, portanto, um investidor que viveu através da amostra teria sido capaz de construir as medidas em cada ponto no tempo usando somente informação disponível. Dessa forma, os resultados fornecem evidências que alguns modelos foram úteis no sentido de guiar os investidores em suas decisões de investimento.

\footnotetext{
${ }^{1}$ Existe certa ambiguidade em relação ao termo "previsão" na literatura. Usa-se o termo de previsibilidade dentro da amostra (in-sample) quando consideramos a amostra inteira e previsibilidade fora da amostra (outsample) quando usamos somente informação disponível contemporaneamente.
} 
Por fim, consideramos a recente corrente da literatura que atesta que combinações das estimativas tende a melhorar à estimação do prêmio de risco (CHIN e POLK, 2015; DUARTE e ROSA, 2015; RAPACH, STRAUSS e ZHOU, 2010). Para testar tal abordagem, realizamos algumas combinações de informação dos modelos individuais. Assim, encontramos que a combinação tende a melhorar a previsibilidade e estabilizar as previsões.

O trabalho foi dividido em seis seções. Na próxima, apresentamos uma breve revisão da literatura. Depois, destacamos os dados utilizados. Na quarta seção, explicamos os modelos propostos pela literatura e, em seguida, na quinta seção, apresentamos duas propostas de extensões aos modelos de dividendos descontados. Por fim, na sexta seção testamos os modelos e apresentamos técnicas de combinação de informação considerando o prêmio de curto, médio e longo prazo. 


\section{PRÊMIO DE RISCO}

Podemos definir o prêmio de risco de mercado como o retorno adicional à taxa de juros livre de risco que o investidor espera receber quando investe seus recursos no mercado de ações. Este retorno seria exigido de tal forma a compensálo pelo risco adicional que ele assume quando investe seus recursos num ativo arriscado em detrimento de um ativo livre de risco. Visto que a compensação dependerá do futuro desempenho do mercado de ações, temos que as abordagens de estimação do prêmio de risco são fundamentalmente modelos de expectativas de retornos dos investidores. Seguindo o padrão adotado por Duarte e Rosa (2013), podemos representar o ERP (equity risk premium ${ }^{2}$ ) matematicamente decompondo os retornos das ações num componente esperado e num componente aleatório não previsível:

$$
R_{t+k}=E_{t}\left[R_{t+k}\right]+\text { erro }_{t+k}
$$

$\mathrm{Na}$ equação acima, o retorno realizado entre o período $t$ e $t+k$ é representado por $R_{t+k}$, o retorno esperado entre o período $t$ e $t+k$, usando $\circ$ conjunto informacional do período $t$, é representado por $E_{t}\left[R_{t+k}\right]$ e, por fim, temos a variável aleatória errot $_{t+k}$. Esta variável não é conhecida no período $t$, mas é realizada no período $t+k$. Portanto, o ERP no tempo $t$ para o horizonte $k$ é definido como:

$$
E R P_{t}(k)=E_{t}\left[R_{t+k}\right]-R_{t+k}^{f}
$$

Nesta equação, $R_{t+k}^{f}$ representa a taxa de juros livre de risco para um investimento de $t$ a $t+k$. Note pela definição do prêmio de mercado acima que o retorno esperado pode mudar no tempo quando novas informações surgem. Logo, por se tratar de uma expectativa de retorno (ou média dos retornos esperados), o prêmio esperado não é garantido. Sendo assim, podemos obter prêmios realizados baixos ou negativos em alguns períodos do tempo. Contudo, prêmios realizados negativos constituem surpresas ao investidor e não existe motivação para ele se sujeitar a ativos arriscados e registrar sistematicamente prejuízos por essa ação.

\footnotetext{
${ }^{2} \mathrm{O}$ equity risk premium também é conhecido na literatura como: market risk premium, market premium, risk premium, discount rate e expected return.
} 
A expectativa dos investidores em relação ao futuro desempenho do mercado de ações não é uma variável observável. Devido a isto, precisamos usar dados econômicos e financeiros para inferir uma estimativa. Desta forma, os modelos de prêmios de riscos são basicamente modelos de expectativas dos investidores e as diferenças entre as abordagens estão, basicamente, na maneira em que estas expectativas são inferidas. Devido a isto, prêmio de risco e retorno esperado é frequentemente usado como sinônimo na literatura (COCHRANE, 2011).

As expectativas dependem da chegada de novas informações que, por sua vez, possui um componente aleatório não conhecido. Consequentemente, existe um razoável grau de incerteza nos modelos de estimação do retorno esperado. De fato, é um tema que apresenta um desafio considerável, pouco consenso e ainda é uma ativa área de pesquisa. Penman (2001) destaca que o prêmio de risco é um grande palpite e que ainda não existe um método solido para estima-lo. Goyal e Welch (2008) destacam que a literatura é difícil de ser absorvida. Isto porque, diferentes técnicas, variáveis e cortes na série pode causar uma variação considerável na estimação. Além disso, eles apontam que alguns artigos contradizem outros e os resultados podem mudar quando dados mais recentes são absorvidos. Delong e Margin (2009) chama atenção para o fato de não existir consenso nas explicações do prêmio. Cochrane (2011) enfatiza que sua pesquisa em relação ao prêmio de risco apresenta mais questões que respostas. Fernandez (2013) afirma que o prêmio de risco é um dos parâmetros mais importante e difícil de descrever em finanças. Damodaran (2013) destaca que, apesar da sua importância, é surpreendente como a estimação do prêmio de risco permanece aleatória na pratica. Mesmo em mercados desenvolvidos ainda não há consenso de qual seria a melhor estimativa para tal prêmio. Neste sentido, Fernandez (2015a) faz uma profunda revisão da literatura e encontra que as estimações do prêmio de risco americano variam entre $3 \%$ a $10 \%$ e reitera que a falta de consenso cria muita confusão entre estudantes e profissionais sobre o prêmio de mercado.

$\mathrm{Na}$ ultima década, presenciamos uma forte mudança no que é considerado ser a melhor fonte de informação para estimar o prêmio. Durante vários anos a média histórica dos retornos realizados foi usada como a melhor estimativa para os retornos futuros. Isto porque, na década de 1960 e 1970, baseados na hipótese de mercados eficientes, acreditava-se que o prêmio de risco era constante no tempo (CAMPBELL, 2007). No entanto, na década de 1980, começaram a surgir 
evidências de previsibilidade dos retornos. Neste período, diversos autores sugeriram que as razões de avaliação dividendo-preço e lucro-preço possuíam significativa capacidade preditiva. Desta forma, altas razões de avaliação seria um forte sinalizador que o mercado estaria avaliando as empresas abaixo do valor de fundamento e, consequentemente, deveríamos esperar altos retornos subsequentes. Campbell (2007) destaca que estes resultados sugeriram que o prêmio de risco seria uma variável de estado, cujo valor deveria ser inferido em cada ponto do tempo. Para Cochrane (2011), atualmente, a questão central da organização da pesquisa em precificação de ativos se deve a variação do prêmio de risco.

O prêmio de risco influência a alocação de riqueza entre diferentes tipos de ativos e, consequentemente, tem fortes desdobramentos sobre a economia como um todo (DAMODARAN, 2013). A relevância de uma estimativa razoável do prêmio de mercado não se limita aos modelos teóricos de apreçamento de ativos. Decisões de investimentos são geralmente baseadas em fluxos de caixas descontados pelo custo de capital das empresas. As taxas de descontos, por sua vez, são obtidas a partir de uma proporção do prêmio de mercado. Concessões públicas e Parcerias Público Privadas muitas vezes especificam uma Taxa Interna de Retorno que também podem ser justificadas a partir de uma proporção do prêmio de mercado. Recentemente, a literatura tem destacado a importância do prêmio de risco como indicador na evolução da futura atividade econômica. Devido a importantes implicações sobre a economia real, os bancos centrais possuem uma significativa preocupação com os movimentos dos preços das ações. Isso porque, um aumento dos preços das ações pode conduzir a um aumento do consumo e investimento agregado. Desta forma, o prêmio também é visto como um importante indicador para decisões de política fiscal e monetária (DUARTE e ROSA, 2013; CHIN e POLK, 2015; RAPACH, STRAUSS e ZHOU, 2010). 


\section{FONTE DOS DADOS}

Nas abordagens selecionadas neste trabalho, usamos fontes de dados variadas. Para os dados americanos, usamos os fornecidos no site do professor Damodaran $^{3}$ e da base do Federal Reserve Bank of St. Louis ${ }^{4}$. No caso dos dados brasileiros, nossas principais fontes foram à base do Economática e IPEADATA. A tabela 1 abaixo apresenta um resumo dos dados utilizados em cada metodologia. Os modelos estimados usam informação do período compreendido entre dezembro de 1999 a dezembro de 2014. A relação de todos os tickers selecionados encontrase no Apêndice A1. Para maiores informações sobre a construção das variáveis e modelos, apresentamos um resumo no Apêndice A5. No caso dos modelos de cross-section, a relação dos tickers selecionados encontra-se no Apêndice A3. Para estes modelos, usamos informação do período compreendido entre janeiro de 2001 a dezembro de 2014.

\footnotetext{
${ }^{3}$ http://pages.stern.nyu.edu/ adamodar/New Home_Page/datafile/
}

${ }^{4}$ https://research.stlouisfed.org/fred2/series/SP500/downloaddata 
Tabela 1 - Fonte dos Dados

\begin{tabular}{|c|c|c|c|}
\hline MODELO & DADOS & FONTE & FREQUÊNCIA \\
\hline \multirow[t]{2}{*}{ Média Histórica } & 1. Selic & 1. IPEA & 1. Mensal \\
\hline & 2. Ibovespa & 2. IPEA & 2. Mensal \\
\hline Modelo de & 1. Swap-pre 360 dias & 1. IPEA & 1. Mensal \\
\hline \multirow[t]{2}{*}{ Gordon } & 2. Dividendo preço & 2. Economática & 2. Mensal \\
\hline & 3. Valor de Mercado & 3. Economática & 3. Mensal \\
\hline Gordon com & 1. Swap-pre 360 dias & 1. IPEA & 1. Mensal \\
\hline \multirow[t]{3}{*}{ Recompras } & 2. Dividendo preço & 2. Economática & 2. Mensal \\
\hline & 3. Valor de Mercado & 3. Economática & 3. Mensal \\
\hline & $\begin{array}{l}\text { 4. Ações em } \\
\text { Tesouraria }\end{array}$ & 4. Economática & 4. Mensal \\
\hline Dois Estágios de & 1. Swap-pre 360 dias & 1. IPEA & 1. Mensal \\
\hline \multirow[t]{3}{*}{ Crescimento } & 2. Dividendo preço & 2. Economática & 2. Mensal \\
\hline & 3. Valor de Mercado & 3. Economática & 3. Mensal \\
\hline & 4. Lucro Líquido & 4. Economática & 4. Anual \\
\hline Taxa de & 1. Swap-pre 360 dias & 1. IPEA & 1. Mensal \\
\hline Crescimento & 2. Dividendo preço & 2. Economática & 2. Mensal \\
\hline \multirow[t]{4}{*}{ Sustentável } & 3. Dividendo por ação & 3. Economática & 3. Mensal \\
\hline & 4. Lucro por ação & 4. Economática & 4. Mensal \\
\hline & 5. Patrimônio Líquido & 5. Economática & 5. Mensal \\
\hline & 6. Lucro Líquido & 6. Economática & 6. Mensal \\
\hline \multirow[t]{8}{*}{ Cross-Section } & 1. Selic & 1. IPEA & 1. Mensal \\
\hline & 2. Inflação & 2. IPEA & 2. Mensal \\
\hline & 3. Retorno das ações & 3. Economática & 3. Mensal \\
\hline & 4. Valor de Mercado & 4. Economática & 4. Mensal \\
\hline & 5. Excesso de Retorno & 5. Nefin & 5. Diária \\
\hline & 6. SMB & 6. Nefin & 6. Diária \\
\hline & 7. $\mathrm{HML}$ & 7. Nefin & 7. Diária \\
\hline & 8. WML & 8. Nefin & 8. Diária \\
\hline Variáveis & 1. Câmbio & 1. IPEA & 1. Mensal \\
\hline \multirow[t]{6}{*}{ Previsoras } & 2. Selic & 2. IPEA & 2. Mensal \\
\hline & 3. IPCA & 3. IPEA & 3. Mensal \\
\hline & 4. IEC & 4. IPEA & 4. Mensal \\
\hline & 5. Swap - 180 dias & 5. IPEA & 5. Mensal \\
\hline & 6. Swap - 360 dias & 6. IPEA & 6. Mensal \\
\hline & 7. Volatilidade & 7. IPEA & 7. Diária \\
\hline Máxima & 1. Selic & 1. IPEA & 1. Mensal \\
\hline \multirow[t]{3}{*}{ Verossimilhança } & 2. Ibovespa & 2. IPEA & 2. Mensal \\
\hline & 3. Dividendo preço & 3. Economática & 3. Mensal \\
\hline & 4. Valor de Mercado & 4. Economática & 4. Mensal \\
\hline Prêmio relativo & 1. S\&P500 & 1. Bank of St. Louis & 1. Semanal \\
\hline
\end{tabular}




\begin{tabular}{llll}
\hline & 2. 10-year T.Bond & 2. Damodaran & 2. Semanal \\
& 3. Retorno das ações & 3. Economática & 3. Semanal \\
\hline Fama e French & 1. Dividend Yield & 1. Economática & 1. Anual \\
$(2002)$ & 2. Dividendo preço & 2. Economática & 2. Anual \\
& 3. Valor de Mercado & 3. Economática & 3. Anual \\
& 4. Lucro Líquido & 4. Economática & 4. Anual \\
& 5. Swap-pre 360 dias & 5. IPEA & 5. Anual \\
\hline EWMA & 1. Swap-pre 360 dias & 1. IPEA & 1. Mensal \\
& 2. Dividendo preço & 2. Economática & 2. Mensal \\
& 3. Valor de Mercado & 3. Economática & 3. Mensal \\
\hline ARMA & 1. Swap-pre 360 dias & 1. IPEA & 1. Mensal \\
& 2. Dividendo preço & 2. Economática & 2. Mensal \\
& 3. Valor de Mercado & 3. Economática & 3. Mensal \\
\hline
\end{tabular}




\section{MODELOS PROPOSTOS PELA LITERATURA}

Nas próximas seções apresentaremos os resultados de algumas metodologias de estimação do prêmio de risco propostas pela literatura. Selecionamos essas abordagens baseado na literatura recente, citações e disponibilidade de dados.

\subsection{MÉDIA HISTÓRICA}

O argumento por de traz desta metodologia é simples e direto, ou seja, temos que a média dos retornos realizados contém informação para inferir o retorno esperado. Assim, inerente a este método temos a expectativa que os retornos futuros retornaram a média dos retornos passados. Nesse cenário, o investidor estaria olhando para a média dos retornos realizados no passado para formar sua expectativa do futuro desempenho do mercado acionário. Desta forma, implicitamente a tal método temos o pressuposto que o retorno esperado é relativamente constante no tempo (CAMPBELL, 2007). Logo, quando aumentamos o tamanho da série, a média amostral dos retornos realizados deveria convergir para o valor do retorno esperado. Além disso, utilizar séries longas na estimação da média histórica possui a vantagem de reduzir a dispersão e a possibilidade de incorporar a ocorrência de choques ou quebras estruturais presentes na amostra (PASTOR e STAMBAUGH, 2001).

Entretanto, o mercado acionário tem mudado no tempo. Damodaran (2013) destaca que o mercado acionário americano em 1871 era parecido com os mercados emergentes em termos de volatilidade e risco. Assim, dado que as características dos mercados tem alterado no tempo, a proposta de usar uma longa série histórica dos retornos para estimar o prêmio de risco pode gerar resultados que tem pouca relevância para os investidores atuais. Além disso, aqueles que advogam o uso de uma série curta se apoiam no fato que a aversão ao risco média do investidor pode mudar no tempo. Portanto, usar séries mais curtas captariam melhor mudanças nas preferências dos investidores e a variação nas características do mercado. Todavia, tal metodologia apresenta o custo de apresentar uma maior variabilidade do prêmio estimado. 
A tabela 2 abaixo ajuda a ilustrar melhor estes argumentos. Para estimar o prêmio histórico, usamos a diferenças dos retornos médios mensais do lbovespa e da Selic, sendo que, o início da amostra corresponde a janeiro de 1995. Conforme esperado, o prêmio estimado por meio da média histórica foi mais estável que o prêmio estimado usando a média móvel dos últimos 5 anos. Além disso, verificamos uma alta variabilidade entre as estimativas do prêmio. Para 2015, temos que o prêmio estimado via média histórica, média móvel dos últimos 10 anos e média móvel dos últimos 5 anos foram de $0.24 \%,-2.01 \%$ e $-13.13 \%$, respectivamente.

Tabela 2 - Prêmios Realizados

\begin{tabular}{cccc}
\hline & Prêmio Histórico & Média Móvel de 10 anos & Média Móvel de 5 anos \\
\hline 2012 & $2.29 \%$ & $3.81 \%$ & $-2.72 \%$ \\
2013 & $2.21 \%$ & $7.06 \%$ & $-7.60 \%$ \\
2014 & $0.83 \%$ & $-0.63 \%$ & $-0.99 \%$ \\
2015 & $0.24 \%$ & $-2.01 \%$ & $-13.13 \%$ \\
\hline
\end{tabular}

Nota: Usamos os dados numa frequência mensal e, em seguida, anualizamos. O inicio da amostra do prêmio histórico corresponde a janeiro de 1995 e o fim a dezembro do ano antecedente. A média móvel corresponde à média dos retornos mensais de 10 e 5 anos prévios.

\subsection{MODELOS DE DIVIDENDOS DESCONTADOS}

Os Modelos de Dividendos Descontados (MDD) parte do principio que o valor da ação é determinado pelo fluxo de caixa que ela produzirá para seus acionistas. Pelo Modelo de Gordon (1962), temos que o preço atual da ação deveria ser igual à soma dos dividendos futuros esperado, descontando uma taxa que leva em consideração o risco e o valor no tempo do dinheiro:

$$
P_{t}=E_{t} \sum_{k=0}^{\infty} \frac{D_{t+k}}{r_{t+k}}
$$

Onde $P_{t}$ é o preço corrente das ações, $E_{t}$ é o operador de esperança condicional, $D_{t}$ é o nível de dividendos corrente, $D_{t+k}$ é o nível dos dividendos $k$ períodos à frente e $r_{t+k}$ é a taxa de desconto para o período $t+k$. Podemos decompor está taxa de desconto da seguinte forma:

$$
r_{t+k}=1+R_{t+k}^{f}+E R P_{t}(k)
$$


Por meio da equação acima, verificamos que implícito a taxa de desconto temos o ERP. Devido a isto, o prêmio de risco estimado via Modelo de Dividendos Descontados também é conhecido na literatura como Prêmio de Risco Implícito.

\subsubsection{Modelo de Gordon}

Quando os investidores precificam ativos, eles estão implicitamente dizendo o quanto eles requerem de retorno esperado. Consequentemente, o preço corrente da ação, juntamente com o fluxo de dividendos esperado, deveria render uma estimativa do prêmio de risco de mercado. Muitos analistas são favoráveis ao uso dos dividendos como mensuração de fluxo de caixa devido ao fato de ser um dos poucos indicadores que é observável e ser considerado como um fluxo de caixabase, dado que grande parte das empresas tende a fixar os dividendos em um patamar que conseguem sustentar no longo-prazo. Logo, os dividendos podem ser considerados como um piso para o fluxo de caixa (DAMODARAN, 2007). Nesta seção, usaremos os dividendos pagos como estimativa do fluxo de caixa, porém, nas próximas seções consideraremos outras estratégias empíricas. Desta forma, considerando que a taxa de crescimento dos dividendos seja uma constante $g$, podemos reescrever a equação acima da seguinte forma:

$$
P_{t}=\frac{D_{t}(1+g)}{1+r}+\frac{D_{t}(1+g)^{2}}{(1+r)^{2}}+\frac{D_{t}(1+g)^{3}}{(1+r)^{3}} \ldots
$$

Isolando o $E R P_{t}$, chegamos ao prêmio de risco de mercado do modelo de dividendos descontados:

$$
E R P_{t}=\frac{D_{t}}{P_{t}}(1+g)+g-R_{t}^{f}
$$

$\mathrm{Na}$ equação acima, $D_{t} / P_{t}(1+g)+g$ representa a estimativa para $\circ$ retorno esperado. Logo, podemos reescrever da seguinte forma:

$$
E R P_{t}=E_{t}\left[R_{t}\right]-R_{t}^{f}
$$

Para implementar esta metodologia, baixamos do Economática as séries de dividendo-preço e a de valor de mercado para todos os tickers elegíveis. Em seguida, agregamos para obter uma série de dividendo-preço do mercado. 
Entretanto, ponderamos o valor da razão dividendo-preço de cada ticker pela sua participação relativa no valor de mercado agregado de cada mês. Em outros termos:

$$
\left(\frac{D}{P}\right)_{t, i}^{p o n d}=\frac{V M_{t, i}}{\sum_{i=1}^{n} V M_{t, i}}\left(\frac{D}{P}\right)_{t, i}
$$

Na equação acima, $V M_{t, i}$ representa o valor de mercado do ticker $i$ no tempo $t$, sendo que, nossa amostra $n$ é constituída por 163 tickers. Desta forma, $V M_{t, i} / \sum_{t=1}^{n} V M_{t, i}$ representa a ponderação. Em seguida, agregamos a série $(D /$ $P)_{t, i}^{\text {pond }}$ de todos os tickers para obter a razão dividendo-preço ponderada do mercado:

$$
\left(\frac{D}{P}\right)_{t}^{\text {Mercado }}=\sum_{i=1}^{n}\left(\frac{D}{P}\right)_{t, i}^{p o n d}
$$

O próximo passo é estimar a taxa de crescimento dos dividendos e, para isso, usamos a metodologia sugerida por Cochrane (2011):

$$
g_{t+1}=\frac{\left(D_{t+1} / P_{t+1}\right)}{\left(D_{t} / P_{t}\right)}-1
$$

Calculando a taxa de crescimento média anual dos dividendos acima para o período compreendido entre dezembro de 1999 a dezembro de 2014, chegamos numa estimativa de $10.26 \%{ }^{5}$. Em seguida, calculamos o retorno esperado, o prêmio implícito e apresentamos esses resultados na tabela 3 abaixo.

Tabela 3 - Modelo de Gordon

\begin{tabular}{ccccc}
\hline & D/P & Retorno Esperado & Swap & Prêmio Implícito \\
\hline 2012 & $4.6 \%$ & $15.4 \%$ & $10.0 \%$ & $5.4 \%$ \\
2013 & $3.9 \%$ & $14.6 \%$ & $7.1 \%$ & $7.5 \%$ \\
2014 & $3.8 \%$ & $14.4 \%$ & $10.6 \%$ & $3.8 \%$ \\
2015 & $4.9 \%$ & $15.6 \%$ & $13.0 \%$ & $2.6 \%$ \\
\hline
\end{tabular}

\footnotetext{
${ }^{5}$ Outra forma de estimar tal número seria por meio do índice chamado BM\&FBovespa Dividendos cujo objetivo é medir o comportamento das ações das empresas que se destacaram em termos de remuneração dos investidores sob a forma de dividendos. As ações elegíveis para o índice é composta pelas empresas listadas na BM\&Bovespa que apresentaram as maiores razões dividendo-preço nos últimos 24 meses anteriores a seleção da carteira. Estimando a taxa de crescimento média deste índice para o período compreendido entre 2006 a 2014 , chegamos numa taxa de crescimento de $15 \%$.
} 
Vale destacar que a abordagem acima apresenta limitações se as empresas não pagam o que elas podem em dividendos (isto é, se elas seguram caixa) e se os lucros apresentarem um forte crescimento no curto prazo. Para contornar esses problemas, surgiram novas abordagens que serão discutidas nas próximas seções.

\subsubsection{Modelo de Gordon com Recompras}

Os principais meios de devolver recursos aos acionistas são: dividendos, recompra de ações, contratos a termo e cisões totais ou parciais. No caso americano, a recompra de ações tornou-se um importante meio de devolver recursos aos acionistas, sendo que, em alguns anos, o valor de recompra de ações superou o valor de dividendos pagos ${ }^{6}$ (MENSA et al, 2014). Consequentemente, deixar o valor das recompras de ações fora do Modelo de Gordon tende subestimar o valor do prêmio de risco implícito. Assim, adicionar o valor das recompra aos dividendos pagos deveria nós dar uma melhor medida do fluxo de caixa total da ação:

$$
E R P_{t}=\left(\frac{D_{t}}{P_{t}}+\frac{R_{t}}{V M_{t}}\right)(1+g)+g-R_{t}^{f}
$$

Para calcular o valor das recompras $R_{t}$ usamos a série fornecida pelo Economática denominada quantidade de ações na Tesouraria. Esta série representa as ações adquiridas pela própria companhia. Desta forma, toda variação positiva nessa conta corresponde à quantidade de recompra de ações. Logo, calculamos as variações positiva da série numa frequência mensal e, em seguida, multiplicamos pelo preço corrente da ação, dividimos pelo valor de mercado $V M_{t}$ e agregamos para obter o valor anual. Em seguida, acrescentamos ao Modelo de Gordon padrão e obtemos as estimativas da tabela 4 abaixo. Com isso, conforme podemos notar por meio da tabela, tivemos um pequeno acréscimo de $0.3 \%$ na estimativa do prêmio implícito de 2015.

\footnotetext{
${ }^{6}$ Basicamente, existem dois fortes incentivos para empresas devolverem recursos via recompras: (i) o mercado punem empresas que interrompem o pagamento de dividendos; (ii) no caso americano, diversos contratos de recompensa dos administradores passaram a depender dos lucros por ação (razão que diminui com o número de ações em circulação) (DAMODARAN, 2007; MENSA et al, 2014)
} 
Tabela 4 - Gordon com Recompras

\begin{tabular}{ccccc}
\hline & D/P + R/VM & Retorno Esperado & Swap & Prêmio Implícito \\
\hline 2012 & $5.2 \%$ & $16.0 \%$ & $10.0 \%$ & $6.0 \%$ \\
2013 & $4.1 \%$ & $14.8 \%$ & $7.1 \%$ & $7.7 \%$ \\
2014 & $4.0 \%$ & $14.7 \%$ & $10.6 \%$ & $4.1 \%$ \\
2015 & $5.1 \%$ & $15.9 \%$ & $13.0 \%$ & $2.9 \%$ \\
\hline
\end{tabular}

\subsubsection{Modelo de Dois Estágios de Crescimento}

Duarte e Rosa (2013) apresenta a proposta de estimar o $g$ usando dois estágios de crescimento. O primeiro estágio corresponde ao crescimento esperado dos lucros dos próximos cinco anos e, o segundo, corresponde a uma estimativa de crescimento do lucro de longo prazo. Por meio desta abordagem, podemos reescrever o Modelo de Gordon da seguinte forma:

$$
E R P_{t}=\frac{D_{t}\left[1+g_{L R}+5\left(g_{S R}-g_{L R}\right)\right]}{P_{t}}+g_{L R}-R_{t}^{f}
$$

Onde $g_{L R}$ representa a estimativa de longo prazo do crescimento dos lucros e $g_{S R}$ representa a estimativa de curto prazo. Realizamos um procedimento análogo ao que fizemos para calcular a taxa de crescimento média dos dividendos usando a série lucro-preço. Em seguida, usamos a taxa média de crescimento dos lucros de cinco anos prévios para estimar o crescimento dos lucros de curto prazo. Para o longo prazo, calculamos a taxa média anual de crescimento dos lucros em todo o período e, desta forma, obtemos uma estimativa de $13.5 \%$. Assim, chegamos às estimativas da tabela 5 abaixo.

Tabela 5- Modelo de Dois Estágios

\begin{tabular}{cccccc}
\hline & $\mathrm{D} / \mathrm{P}$ & $\boldsymbol{g}_{S R}$ & Retorno Esperado & Swap & Prêmio \\
\hline 2012 & $4.6 \%$ & $9.8 \%$ & $20.2 \%$ & $10.0 \%$ & $10.2 \%$ \\
2013 & $3.9 \%$ & $5.8 \%$ & $17.3 \%$ & $7.1 \%$ & $10.2 \%$ \\
2014 & $3.8 \%$ & $-11.8 \%$ & $5.8 \%$ & $10.6 \%$ & $-4.8 \%$ \\
2015 & $4.9 \%$ & $-1.7 \%$ & $12.3 \%$ & $13.0 \%$ & $-0.7 \%$ \\
\hline
\end{tabular}

\subsubsection{Modelo da Taxa de Crescimento Sustentável}

Segundo Damodaran (2007), a política de dividendos de uma empresa tende a seguir o seu ciclo de vida e este ciclo seria caracterizado em termos de 
oportunidades de investimento e crescimento. Empresas com grandes oportunidades de crescimento não pagam muito dividendos, enquanto que as empresas estáveis (como menores oportunidades de projetos para investir) tendem a pagar mais dividendos. Consequentemente, tal fato influencia o valor da estimativa da taxa de crescimento média dos dividendos. No entanto, esta taxa de crescimento pode ser reescrita de muitas maneiras alternativas, sendo que, cada forma apresenta uma estratégia empírica distinta para inferir o retorno esperado da ação (CAMPBELL, 2007). De acordo com Damodaran (2007), as empresas que possuem altas razões de retenção do lucro (baixo payout) e obtém altos ROE (Return on Equity) deveriam apresentar taxas de crescimento do lucro por ação mais altas. Se pressupusermos que o retorno sobre o patrimônio líquido não se altere, ou seja, $R O E_{t}=R O E_{t-1}=R O E$, a taxa de crescimento do lucro líquido pode ser reescrita da seguinte forma ${ }^{7}$ :

$$
g=\left(1-\frac{D}{L}\right) R O E
$$

Onde $R O E$ é o retorno sobre o patrimônio líquido (igual ao lucro líquido do exercício dividido pelo patrimônio líquido inicial), $D / L$ é a razão de payout e (1$D / L$ ) representa a taxa de retenção de lucros. A taxa de crescimento acima é conhecida na literatura como taxa de crescimento sustentável ${ }^{8}$. O significado de sustentável se refere à capacidade da empresa de crescer sem esgotar a capacidade de continuidade. O ROE é uma medida de lucratividade e a taxa de retenção dos lucros (payout) é uma medida de reinvestimento. Maiores níveis de reinvestimento, aumenta o crescimento sustentável. Isso é bastante razoável uma vez que a empresa tende a reter recursos dos acionistas para os investimentos necessários na fase de crescimento. Minardi e Sanvicente (2006) e Campbell (2007) usam a metodologia acima no Modelo de Gordon. Desta forma, o retorno esperado pode ser representado da seguinte forma:

$$
R_{D P}=\frac{D}{P}+\left(1-\frac{D}{L}\right) R O E
$$

\footnotetext{
${ }^{7}$ Apresentamos a demonstração usada por Damodaran (2007) no Apêndice A2.

${ }^{8} \mathrm{O}$ conceito de taxa de crescimento sustentável foi originalmente proposto por Robert C. Higgins em seu trabalho How much growth can a firm afford? (HIGGINS, 1977)
} 
Campbell (2007) calcula a média histórica dos dados dos payouts e lucratibilidade (ROE), obtendo um $g$ constante no tempo ${ }^{9}$. No caso da razão de avaliação dividendo-preço, ele usa os valores correntes para obter um retorno esperado condicional a atual avaliação do mercado. Realizando um procedimento análogo para o Brasil, encontramos um payout médio de 58.3\% e um ROE médio de $17.2 \%$, resultando assim, numa taxa de crescimento sustentável de $7.2 \%$. Apresentamos os resultados dessa metodologia na tabela 6 abaixo.

Tabela 6 - Taxa de Crescimento Sustentável

\begin{tabular}{cccc}
\hline & D/P & Retorno Esperado & Prêmio \\
\hline 2012 & $4.6 \%$ & $12.1 \%$ & $2.1 \%$ \\
2013 & $3.9 \%$ & $11.4 \%$ & $4.3 \%$ \\
2014 & $3.8 \%$ & $11.2 \%$ & $0.6 \%$ \\
2015 & $4.9 \%$ & $12.4 \%$ & $-0.6 \%$ \\
\hline
\end{tabular}

\subsection{REGRESSÕES DE CROSS-SECTIONAL}

Basicamente, está abordagem consiste em duas etapas. Na primeira, estimamos a seguinte série de tempo:

$$
R_{t+k}^{i}-R_{t+k}^{f}=\alpha_{t+k}^{i} X_{t+k}+\beta_{t+k}^{i} \text { Fatores }_{t+k}+e_{t+k}^{i}
$$

$\mathrm{Na}$ equação acima, $R_{t+k}^{i}$ representa o retorno realizado do portfolio ou ativo entre o período $t$ até $t+k$ e $X_{t+k}$ representa as variáveis de estado. Estas variáveis podem ser quaisquer indicadores econômicos que ajuda a identificar mudanças no conjunto de oportunidade de investimento, podendo inclusive, incluir uma constante. Por fim, Fatores $s_{t+k}$ representa os fatores de risco (DUARTE e ROSA, 2013). Na segunda etapa, estimamos a cross-sectional regredindo excesso de retorno nos betas estimados na equação acima:

$$
R_{t+k}^{i}-R_{t+k}^{f}=E R P_{t}(k) \hat{\beta}_{t+k}^{i}
$$

\subsubsection{Modelos de Fatores de Risco}

Markowitz (1959), Sharpe (1964) e Lintner (1965) fundamentaram o modelo de equilíbrio geral de apreçamento de ativos financeiros CAPM e, tal fato,

\footnotetext{
${ }^{9}$ Minardi e Sanvicente (2006) partem de uma abordagem diferente e estimam a taxa de crescimento variando no tempo.
} 
marca o nascimento da teoria de precificação de ativos. Neste modelo, os agentes são homogêneos, não exercem influência sobre o preço dos ativos e a função de utilidade a ser maximizada depende da média e do desvio-padrão dos retornos esperado. Desta forma, os agentes substituem maiores riscos por maiores retornos esperados, sendo o beta a medida de risco relevante para o ativo. Além disso, dado as hipóteses do modelo, todos investidores veem o mesmo conjunto de oportunidade de investimento e, assim, eles possuem o mesmo portfólio de ativos arriscados.

Entretanto, este modelo ignora muitos fatores importantes da vida real e desta forma, tem apresentado pobre desempenho empírico em anos recentes (COCHRANE, 1999). No inicio da década de 1970, apareceram evidências que boa parte da variação do retorno esperado não estava correlacionada com o beta de mercado. Basu (1977) mostrou evidências que a razão lucro-preço afeta os retornos futuros. Statman (1980) e Rosenber, Reid e Lastein (1985) documentaram o efeito do book-to-market e Banz (1981) documentou o efeito tamanho. Bhandari (1988) encontrou que uma alta razão da divida-ação está associada com retornos que são altos relativos aos betas de mercado. Concomitantemente, surgiram outras fortes evidências que razões envolvendo preços de ações têm informação sobre os retornos esperado que não é contemplado pelos betas de mercado.

Desta forma, essas evidências sinalizaram que podemos adicionar variáveis explicativas na estrutura do CAPM. Se toda diferença no retorno esperado são explicado pelo beta, a inclinação média das variáveis adicionadas não deveria ser diferente de zero. Fama e French (1996) destacaram que, a maioria dos padrões não explicados pelo CAPM, desaparece com o modelo de três fatores ${ }^{10}$. Segundo este modelo, o excesso de retorno de um ativo ou portfólio $\left[E\left(R_{i}\right)-R_{f}\right]$ é explicado pelos seguintes fatores: excesso de retorno de um portfolio de mercado $\left(R_{M}-R_{f}\right)$, SMB (small minus big) e HML (high minus low). Podemos representar este modelo da seguinte forma:

$$
E\left(R_{i}\right)-R_{f}=b_{i}\left[E\left(R_{M}\right)-R_{f}\right]+s_{i} E(S M B)+h_{i} E(H M L)
$$

\footnotetext{
${ }^{10}$ Esses padrões estão relacionados as características da firma como: size, earnings/price, cash flow/price, book-to Market equity, past sales growth, long-term past return e short-term past return.
} 
Onde $E\left(R_{M}\right)-R_{f}, E(S M B)$ e $E(H M L)$ representa os prêmios esperados e os parâmetros $b_{i}, s_{i}$ e $h_{i}$ representam as inclinações da seguinte regressão de séries de tempo:

$$
R_{t}^{i}-R_{t}^{f}=\alpha_{i}+\beta_{i}\left(R_{t}^{M}-R_{t}^{f}\right)+s_{i} S M B_{t}+h_{i} H M L_{t}+\varepsilon_{t}^{\mathrm{i}}
$$

Entretanto, segundo Fama e French $(1996,2004)$, o modelo de três fatores acima explica a maioria das anomalias não assimiladas pelo modelo CAPM, exceto a anomalia denominada momento. Com o intuito de contornar essa limitação, surgiu na literatura a proposta do modelo de quatro fatores. Este modelo é semelhante à proposta anterior, a única diferença é que acrescentamos o fator de momento WML (winners minus losers) (CARHART, 1997). Além destes, outro fator de risco proposto pela literatura é o da inflação П (DUARTE e ROSA, 2013). Consequentemente, podemos reescrever o modelo de 3 fatores numa especificação mais geral, ou seja, considerando o fator de momento e inflação:

$$
R_{t+k}^{i}-R_{t+k}^{f}=\alpha_{i}+\beta_{i}\left(R_{t+k}^{M}-R_{t+k}^{f}\right)+s_{i} S M B_{t+k}+h_{i} H M L_{t+k}+w_{i} W M L_{t+k}+p_{i} \Pi_{t+k}+\varepsilon_{t+k}^{\mathrm{i}}
$$

Para chegar ao prêmio de risco de mercado por meio deste modelo, usamos o procedimento de Fama e Macbeth (1973). Este procedimento consistente em rodar a regressão de séries temporais acima e, em seguida, rodar a crosssection abaixo para cada período do tempo:

$$
R_{t+1}^{i}-R_{t+1}^{f}=\hat{\beta}_{i}^{\prime} \lambda_{t}^{\beta}+\hat{s}_{i}^{\prime} \lambda_{t}^{s}+\hat{h}_{i}^{\prime} \lambda_{t}^{h}+\widehat{w}_{i}^{\prime} \lambda_{t}^{w}+\hat{p}_{i}^{\prime} \lambda_{t}^{p}
$$

Calculando a média de $\lambda_{t}^{\beta}$, chegamos à estimativa do prêmio de risco de mercado:

$$
\hat{\lambda}^{\beta}=\frac{1}{T} \sum_{t=1}^{T} \hat{\lambda}_{t}^{\beta}
$$

Onde $E R P_{t}(k)=\hat{\lambda}^{\beta}$. A variância é calculada da seguinte forma:

$$
\sigma^{2}\left(\hat{\lambda}^{\beta}\right)=\frac{1}{T^{2}} \sum_{t=1}^{T}\left(\hat{\lambda}_{t}^{\beta}-\hat{\lambda}^{\beta}\right)^{2}
$$


Definindo $t\left(\hat{\lambda}^{\beta}\right)$ como a estatística $t$, temos:

$$
t\left(\hat{\lambda}^{\beta}\right)=\frac{\hat{\lambda}^{\beta}}{\sigma\left(\hat{\lambda}^{\beta}\right)}
$$

Implementamos está metodologia usando séries dos retornos equally e value weighted. Em outras palavras, nas séries equally weighted damos o mesmo peso para todos os tickers da nossa amostra no momento da agregação. No caso das séries value weighted, o procedimento é idêntico à agregação ponderada da série dividendo-preço realizada na seção correspondente ao Modelo de Gordon. Realizamos as estimações tanto para portfólios quanto para ativos. Entretanto, os resultados dos portfólios não foram significativos e, logo, não reportamos. No caso dos ativos, os resultados foram significativos tanto para equally quanto para value weighted. A tabela 7 abaixo sintetiza os principais resultados da implementação desta metodologia. 
Tabela 7- Fatores de Risco

\begin{tabular}{|c|c|c|c|c|c|c|c|c|c|c|c|c|}
\hline & \multicolumn{4}{|c|}{3 fatores } & \multicolumn{4}{|c|}{4 fatores } & \multicolumn{4}{|c|}{5 fatores } \\
\hline & $\lambda$ & $D P(\lambda)$ & $t(\lambda)$ & Prêmio & $\lambda$ & $D P(\lambda)$ & $t(\lambda)$ & Prêmio & $\lambda$ & $D P(\lambda)$ & $t(\lambda)$ & Prêmio \\
\hline Equally Weighted & 0.0210 & 0.0054 & 3.88 & $28 \%$ & 0.0200 & 0.0055 & 3.67 & $27 \%$ & 0.0195 & 0.0055 & 3.58 & $26 \%$ \\
\hline 2013 & & & & & & & & & & & & \\
\hline Equally Weighted & 0.0205 & 0.0055 & 3.73 & $28 \%$ & 0.0197 & 0.0051 & 3.57 & $26 \%$ & 0.0191 & 0.0055 & 3.46 & $25 \%$ \\
\hline 2014 & & & & & & & & & & & & \\
\hline Equally Weighted & 0.0192 & 0.0052 & 3.74 & $26 \%$ & 0.0186 & 0.0052 & 3.59 & $25 \%$ & 0.0180 & 0.0052 & 3.48 & $24 \%$ \\
\hline Value Weighted & 0.0165 & 0.0056 & 2.98 & $22 \%$ & 0.0140 & 0.0063 & 2.24 & $18 \%$ & 0.0145 & 0.0060 & 2.41 & $19 \%$ \\
\hline 2015 & & & & & & & & & & & & \\
\hline
\end{tabular}




\subsection{REGRESSÕES DE SÉRIES DE TEMPO}

Existe um conjunto de abordagens de estimação do prêmio de risco de mercado que consiste em regredir o excesso de retornos realizados em variáveis econômicas ou financeiras defasadas:

$$
R_{t+k}-R_{t+k}^{f}=\alpha+\beta X_{t}+\text { erro }_{t}
$$

Assim, o ERP é obtido ignorando o termo de erro:

$$
E R P_{t}(k)=\hat{\alpha}+\hat{\beta} X_{t}
$$

Desta forma, esta metodologia procura estimar o componente previsível e esperado do excesso de retorno. A literatura em torno deste tipo de abordagem destaca diversas variáveis com capacidade preditiva para o prêmio de risco. Autores como Campbell e Shiller (1988a,b), Fama e French (1988) e Rozeff (1984) reforçaram que razões de avaliação tais como dividendo-preço e lucro-preço são positivamente correlacionadas com os retornos subsequentes e que a previsibilidade de longo-prazo seria significativa ${ }^{11}$. Outras variáveis que também foram documentadas pela literatura são: câmbio, taxa de juros, inflação, expectativas e volatilidade dos retornos (CAMPBELL e THOMPSON, 2008; GOYAL e WECH, 2008). Destas variáveis, a razão dividendo-preço aparece na literatura como uma das principais para estimar o componente previsível do excesso de retorno (FERNANDEZ, 2013). Isto decorre fundamentalmente da importante relação derivada por Campbell e Shiller (1988a). Esta relação é representada pela seguinte aproximação loglinear da identidade dos retornos:

$$
r_{t+1}=\kappa+\rho p_{t+1}+(1-\rho) d_{t+1}-p_{t}
$$

Podemos reescrever da seguinte forma:

$$
r_{t+1}=\kappa+\left(d_{t}-p_{t}\right)+\Delta d_{t+1}-\rho\left(d_{t+1}-p_{t+1}\right)
$$

Onde $r_{t+1}$ representa o log do retorno, $p_{t}$ representa o log do preço, $d_{t} \circ$ log do dividendo e $\rho$ é um coeficiente da loglinearização. Impondo certas condições a equação acima, podemos reescrevê-la assim:

\footnotetext{
${ }^{11}$ Vale destacar que $D_{t} / P_{t-1}$ representa o dividend yield e $D_{t} / P_{t}$ é a razão dividendo-preço. Similarmente, $L_{t} / P_{t-1}$ representa o earnings yield e $L_{t} / P_{t}$ é a razão lucro-preço.
} 


$$
d_{t}-p_{t}=\frac{\kappa}{1-\rho}+E_{t} \sum_{j=0}^{\infty} \rho^{j}\left[r_{t+1+j}-\Delta d_{t+1+j}\right]
$$

Por meio dela, percebemos que uma das razões para a razão dividendopreço ser considerada uma importante variável previsora se deve ao fato dela revelar a expectativa de mercado tanto dos retornos futuros, quanto do crescimento dos dividendos. No passado, diversos estudos sugeriram que os retornos não eram previsíveis e a variação na razão dividendo-preço correspondia à variação nos dividendos esperados. Entretanto, evidências empíricas recentes sugerem que uma variação nos retornos esperados repercute inteiramente numa variação da série dividendo-preço. Desta forma, temos que a razão dividendo-preço deveria prever retornos e não crescimento dos dividendos (COCHRANE, 2011; FAMA e FRENCH, 2002). Assim, a equação acima ajuda a motivar regressões dos retornos das ações na razão dividendo-preço. Empiricamente, uma alta razão dividendo-preço deveria prever altos retornos e, consequentemente, esta razão contêm informação sobre o ERP (CAMPBELL, 2007; COCHRANE, 2011).

\subsubsection{Estimação por Máxima Verossimilhança}

Uma forma interessante de estimar o prêmio de mercado é usar informações contidas tanto na razão dividendo-preço, quanto informações fornecidas pelos choques dessa série. Com este intuito, Wachter e Avdis (2014) sugerirão mensurar o prêmio de mercado usando estimação por Máxima Verossimilhança. Para isso, eles propõem o seguinte modelo estatístico:

$$
\begin{aligned}
& r_{t+1}-\mu_{r}=\beta\left(x_{t}-\mu_{x}\right)+u_{t+1} \\
& x_{t+1}-\mu_{x}=\theta\left(x_{t}-\mu_{x}\right)+v_{t+1}
\end{aligned}
$$

Onde $r_{t+1}=\log \left(1+R_{t+1}\right)-\log \left(1+R_{f, t+1}\right)$ e $x_{t}$ representa o log da razão dividendo-preço. Temos que $\mu_{r}$ é o prêmio de risco e que $\mu_{x}$ é a media de $x_{t}$. $\mathrm{O}$ vetor de choques $\left[u_{t+1}, v_{t+1}\right]^{T}$ condicional em $\left(r_{1}, \ldots, r_{t}, x_{0}, \ldots, x_{t}\right)$ é normalmente distribuído ${ }^{12}$ com média zero e matriz de covariância:

\footnotetext{
${ }^{12}$ Embora os autores foquem no caso que os choques são normalmente distribuídos, eles também exploram a robustez de distribuições alternativas.
} 


$$
\Sigma=\left[\begin{array}{cc}
\sigma_{u}^{2} & \sigma_{u v} \\
\sigma_{u v} & \sigma_{v}^{2}
\end{array}\right]
$$

Assim, podemos estimar os parâmetros $\mu_{r}, \mu_{x}, \beta, \theta, \sigma_{u}^{2}, \sigma_{v}^{2}$ e $\sigma_{u v}$ usando a seguinte função de verossimilhança:

$$
\begin{gathered}
p\left(r_{1}, \ldots, r_{T} ; x_{0}, \ldots, x_{T} \mid \mu_{r}, \mu_{x}, \beta, \theta, \Sigma\right)= \\
\left(2 \pi \sigma_{x}^{2}\right)^{-\frac{1}{2}} \exp \left\{-\frac{1}{2}\left(\frac{x_{0}-\mu_{x}}{\sigma_{x}}\right)^{2}\right\} x \\
|2 \pi \Sigma|^{-\left(\frac{T}{2}\right)} \exp \left\{-\frac{1}{2}\left(\frac{\sigma_{v}^{2}}{|\Sigma|} \sum_{t=1}^{T} u_{t}^{2}-\frac{2 \sigma_{u v}}{|\Sigma|} \sum_{t=1}^{T} u_{t} v_{t}+\frac{\sigma_{u}^{2}}{|\Sigma|} \sum_{t=1}^{T} v_{t}^{2}\right)\right\}
\end{gathered}
$$

Apresentamos no Apêndice A4 o procedimento geral para estimar os parâmetros $\mu_{r}, \mu_{x}, \beta, \theta, \sigma_{u}^{2}, \sigma_{v}^{2}$ e $\sigma_{u v}$. Basicamente, se resume em reescrever 0 conjunto de condições de primeira ordem derivadas da equação acima. Implementamos esta metodologia e apresentamos as estimativas dos parâmetros na tabela 8 abaixo.

Tabela 8 - Parâmetros estimados

\begin{tabular}{ccccc}
\hline & 2012 & 2013 & 2014 & 2015 \\
\hline$\mu_{r}$ & 0.03 & 0.13 & 0.07 & -0.09 \\
$\mu_{x}$ & -3.24 & -3.29 & -3.30 & -3.22 \\
$\beta$ & -0.15 & -1.80 & -1.72 & -1.56 \\
$\theta$ & 0.99 & 0.99 & 0.99 & 0.99 \\
$\sigma_{u}$ & 3.34 & 3.36 & 3.28 & 3.25 \\
$\sigma_{v}$ & 0.08 & 0.08 & 0.08 & 0.08 \\
$\rho_{u v}$ & -0.04 & -0.04 & -0.03 & -0.03 \\
\hline
\end{tabular}

Nota: Estimativas de:

$$
\begin{aligned}
& r_{t+1}-\mu_{r}=\beta\left(x_{t}-\mu_{x}\right)+u_{t+1} \\
& x_{t+1}-\mu_{x}=\theta\left(x_{t}-\mu_{x}\right)+v_{t+1}
\end{aligned}
$$

Os dados estão numa frequência mensal, com início em dezembro de 1999 e o fim em dezembro de cada ano anterior ao destacado na primeira linha. Por exemplo, os valores dos parâmetros de 2012 corresponde a amostra compreendida entre dezembro de 1999 a dezembro de 2011. Por fim, $r_{t}$ representa o log do excesso de retorno do lbovespa sobre a Selic e $x_{t}$ o log da razão dividendo-preço ponderada pelo valor de mercado.

Definindo $\hat{\mu}_{r}$ como a estimativa de máxima verossimilhança do prêmio de mercado. Podemos definir a série de tempo dos choques $\hat{u}_{t}$ e $\hat{v}_{t}$ da seguinte forma: 


$$
\begin{aligned}
& \hat{u}_{t}=r_{t}-\hat{\mu}_{r}-\hat{\beta}\left(x_{t-1}-\hat{\mu}_{x}\right) \\
& \hat{v}_{t}=x_{t}-\hat{\mu}_{x}-\hat{\theta}\left(x_{t-1}-\hat{\mu}_{x}\right)
\end{aligned}
$$

Logo:

$$
\hat{\mu}_{r}=\frac{1}{T} \sum_{t=1}^{T} r_{t}-\frac{1}{T} \sum_{t=1}^{T} \hat{u}_{t}-\hat{\beta} \frac{1}{T} \sum_{t=1}^{T}\left(x_{t-1}-\hat{\mu}_{x}\right)
$$

Como podemos ver pela equação acima, existem duas razões pela qual a estimativa por máxima verossimilhança $\hat{\mu}_{r}$ seja diferente da média amostral $\frac{1}{T} \sum_{t=1}^{T} r_{t}$ :

- Se os choques $\hat{u}_{t}$ não tiver média zero

- Se o retornos são previsíveis no sentido que $\beta \neq 0$

Note também que $1 / T \sum_{t=1}^{T} r_{t}$ representa o prêmio realizado histórico. Desta forma, o que o presente modelo diz é que se usarmos a média dos retornos realizados para inferir o futuro comportamento do excesso de retorno, estaríamos deixando de lado duas significativas fontes de informação: os choques dos retornos e o poder explicativo da série dividendo-preço em relação à previsibilidade de retornos. O termo da média dos choques $1 / T \sum_{t=1}^{T} \hat{u}_{t}$ desempenha uma importante função para explicar a diferença entre as duas estimativas. Se aplicarmos uma estimação por OLS, os choques terão média zero por construção. Entretanto, como podemos ver pela equação acima, isto não se verifica quando aplicamos a estimação por máxima verossimilhança. Usando esta abordagem, os choques dos retornos apresentam a seguinte configuração:

$$
\frac{1}{T} \sum_{t=1}^{T} \hat{u}_{t}=\frac{\hat{\sigma}_{u v}}{\hat{\sigma}_{v}^{2}} \frac{1}{T} \sum_{t=1}^{T} \hat{v}_{t}
$$

Pela equação acima, vemos que os choques dos retornos nessa abordagem tem uma ligação direta com os choques na razão dividendo-preço. Sintetizamos os resultados da estimação desta metodologia na tabela 9 abaixo. Como podemos constatar por meio dela, se empregarmos a média amostral para calcular o prêmio brasileiro teríamos um valor negativo de $-0.16 \%$ por mês para o 
ano de 2015. Entretanto, considerando as informações dos choques dos retornos e previsibilidade, encontramos um valor de $-0.09 \%$ por mês.

Tabela 9 - Prêmio de Risco

\begin{tabular}{|c|c|c|c|c|}
\hline & $\hat{\mu}_{r}$ & $\frac{1}{T} \sum_{t=1}^{T} r_{t}$ & $\frac{1}{T} \sum_{t=1}^{T} \hat{u}_{t}$ & $\hat{\beta} \frac{1}{T} \sum_{t=1}^{T}\left(x_{t-1}-\hat{\mu}_{x}\right)$ \\
\hline 2012 & 0.034 & -0.089 & 0.031 & -0.155 \\
\hline 2013 & 0.133 & -0.085 & 0.034 & -0.253 \\
\hline 2014 & 0.074 & -0.143 & 0.034 & -0.252 \\
\hline 2015 & -0.092 & -0.165 & 0.026 & -0.099 \\
\hline
\end{tabular}

Vale lembrar que os autores definem o prêmio de mercado assumindo que o $\log$ dos retornos $\log \left(1+R_{t}\right)$ são normalmente distribuídos. Podemos transformar o resultado para nível da seguinte forma:

$$
E\left[R_{t}\right]=E\left[e^{\log \left(1+R_{t}\right)}\right]-1=e^{E\left[\log \left(1+R_{t}\right)\right]+\frac{1}{2} \operatorname{Var}\left(\log \left(1+R_{t}\right)\right)}-1
$$

Usando a definição do log do excesso de retorno, $E\left[\log \left(1+R_{t}\right)\right]=E\left(r_{t}\right)+$ $E\left[\log \left(1+R_{t}^{f}\right)\right]$, chegamos:

$$
E\left[R_{t}-R_{t}^{f}\right]=e^{E\left[r_{t}\right]} e^{E\left[\log \left(1+R_{t}^{f}\right)\right]+\frac{1}{2} \operatorname{Var}\left(\log \left(1+R_{t}\right)\right)}-1-E\left[R_{t}^{f}\right]
$$

Calculando a equação acima, chegamos aos valores representados na tabela 10 abaixo.

Tabela 10 - Resultados do Modelo

\begin{tabular}{ccccccc}
\hline & $\boldsymbol{E}\left[\boldsymbol{R}_{\boldsymbol{t}}-\boldsymbol{R}_{\boldsymbol{t}}^{f}\right]$ & $\boldsymbol{E}\left[\boldsymbol{r}_{\boldsymbol{t}}\right]$ & $\boldsymbol{E}\left[\log \left(\mathbf{1}+\boldsymbol{R}_{\boldsymbol{t}}^{f}\right)\right]$ & $\boldsymbol{V a r}\left(\log \left(\mathbf{1}+\boldsymbol{R}_{\boldsymbol{t}}\right)\right)$ & $\boldsymbol{E}\left[\boldsymbol{R}_{\boldsymbol{t}}^{f}\right]$ & $\boldsymbol{P r e ̂ m i o}$ \\
\hline 2012 & 0.003 & 0.034 & 0.012 & 0.006 & 0.012 & $4.27 \%$ \\
2013 & 0.004 & 0.133 & 0.011 & 0.006 & 0.012 & $5.38 \%$ \\
2014 & 0.004 & 0.074 & 0.011 & 0.006 & 0.011 & $4.46 \%$ \\
2015 & 0.002 & -0.092 & 0.011 & 0.006 & 0.011 & $2.31 \%$ \\
\hline
\end{tabular}

Nota: Apresentamos o prêmio acima em termos anuais. 


\subsection{OUTRAS ABORDAGENS}

\subsubsection{Prêmio Relativo}

Outra forma de estimar o ERP apontado pela literatura é usando informações de outros países. Segundo Damodaran (2013), podemos estimar o prêmio por meio da diferença de risco existente entre os mercados. Por sua vez, essa diferença de risco é calculada através das volatilidades dos retornos desses mercados. Seguindo essa proposta, calculamos o desvio-padrão dos retornos do Brasil relativo aos Estados Unidos da seguinte forma:

$$
\sigma \text { relativo }_{B R}=\frac{\sigma_{B R}}{\sigma_{E U A}}
$$

Onde $\sigma_{B R}$ e $\sigma_{E U A}$ representam os desvio-padrões dos retornos semanais do Brasil e Estados Unidos, respectivamente. Dado que altos desvio-padrões estão associados com maiores risco, a razão do desvio-padrão dos retornos é uma estimativa para capturar o diferencial de risco existente entre os mercados. Assumindo que o prêmio de risco americano seja estimado pela média histórica, podemos chegar ao prêmio de risco brasileiro usando a estimativa do ERP americano:

$$
E R P_{B R}=E R P_{E U A} \times \text { relativo }_{B R}
$$

Por meio desta metodologia, temos que o ERP brasileiro é igual ao ERP americano multiplicado pela razão do desvio-padrão dos retornos. O prêmio de risco americano estimado por meio da diferença entre a média geométrica dos retornos anuais do S\&P500 e do 10-year T. Bond foi de $4.60 \%{ }^{13}$. Para calcular os retornos semanais do Brasil, baixamos do Economática a série de retorno e a de valor de mercado para todos os tickers selecionados. Em seguida, agregamos os retornos ponderando pelo valor de mercado. Os dados semanais americanos dos retornos correspondem ao S\&P500 e foram obtidos através da base do Federal Reserve Bank of St. Louis ${ }^{14}$. A tabela 11 abaixo apresenta os resultados dos desvios-padrões dos retornos semanais brasileiros e americanos. Em seguida, apresentamos os resultados do ERP (tabela 12).

\footnotetext{
${ }^{13}$ Fonte de dados: $\mathrm{http}: / /$ pages.stern.nyu.edu/ adamodar/New Home_Page/datafile/histretSP.html

${ }^{14}$ https://research.stlouisfed.org/fred2/series/SP500/downloaddata
} 
Tabela 11 - Desvio-padrão dos Retornos

\begin{tabular}{ccc}
\hline & $\boldsymbol{\sigma}_{\text {BR }}$ & $\boldsymbol{\sigma}_{\text {EUA }}$ \\
\hline $01 / 2010-12 / 2011$ & $2.7 \%$ & $2.7 \%$ \\
$01 / 2011-12 / 2012$ & $2.5 \%$ & $2.4 \%$ \\
$01 / 2012-12 / 2013$ & $2.0 \%$ & $1.5 \%$ \\
$01 / 2013-01 / 2014$ & $2.7 \%$ & $1.5 \%$ \\
\hline
\end{tabular}

Tabela 12 - ERP e Prêmio de Risco do País

\begin{tabular}{ccc}
\hline & $\boldsymbol{\sigma}_{\text {relativo }}$ & $\mathbf{E R P}_{\text {BR }}$ \\
\hline 2012 & 0.99 & $5.8 \%$ \\
2013 & 1.02 & $5.9 \%$ \\
2014 & 1.31 & $7.6 \%$ \\
2015 & 1.84 & $10.7 \%$ \\
\hline
\end{tabular}

\subsubsection{Modelo de Fama e French}

Fama e French (2002) sugere estimar o prêmio de mercado usando as taxas de crescimento dos dividendos e dos lucros como uma aproximação da taxa esperada de ganho de capital. Pela identidade dos retornos temos:

$$
r_{t}=\frac{D_{t}+P_{t}}{P_{t-1}}
$$

Podemos reescrevê-la da seguinte forma:

$$
\begin{gathered}
1+R_{t}=\frac{D_{t}}{P_{t-1}}+\frac{P_{t}}{P_{t-1}} \\
R_{t}=\frac{D_{t}}{P_{t-1}}+\frac{P_{t}-P_{t-1}}{P_{t-1}}
\end{gathered}
$$

Tomando a média da equação acima, temos que a média do dividend yield, juntamente com a média da taxa de ganho de capital, oferece-nos uma estimativa do retorno esperado incondicional:

$$
E\left(R_{t}\right)=E\left(D_{t} / P_{t-1}\right)+E\left(G P_{t}\right)
$$

Onde $D_{t}$ é o dividendo para o ano $t, P_{t-1}$ é o preço do fim do ano $t-1$, $G P_{t}=\left(P_{t}-P_{t-1}\right) / P_{t-1}$ é a taxa de ganho de capital e $E()$ indica o valor médio. Se a razão dividendo-preço for estacionária, a média da taxa de crescimento dos 
dividendos anual será uma boa aproximação para a taxa média de ganho de capital anual. Então, uma estimativa alternativa do retorno esperado é:

$$
E\left(R D_{t}\right)=E\left(D_{t} / P_{t-1}\right)+E\left(G D_{t}\right)
$$

Onde $G D_{t}=\left(D_{t}-D_{t-1}\right) / D_{t-1}$ é a taxa de crescimento dos dividendos. No entanto, a razão dividendo-preço pode não ser estacionária devido à mudança na política de dividendos e ao programa de recompras. Neste caso, a taxa de crescimento média dos lucros, $E\left(G L_{t}\right)=E\left(\left(L_{t}-L_{t-1}\right) / L_{t-1}\right)$, surge como uma aproximação alternativa:

$$
E\left(R L_{t}\right)=E\left(D_{t} / P_{t-1}\right)+E\left(G L_{t}\right)
$$

Os autores destacam que usar os fundamentos (dividendos e lucros) para estimar o retorno esperado ajuda a jugar se a média dos retornos realizados está num patamar alto ou baixo relativo ao retorno esperado estimado. Além disso, outra vantagem é que as estimativas do retorno esperado dos fundamentos são menos sensíveis a choques. Isto porque, diversos choques podem afetar o termo de ganho de capital, mas não afetar na mesma proporção os dividendos e lucros.

Outro ponto de destaque é que o dividendo é uma variável de policy, ou seja, uma mudança na política de dividendos pode impactar sua taxa de crescimento. Apesar disso, mudanças na política de dividendo tende a se estabilizar e reverter para uma nova média no longo-prazo. Isto não impede que existam problemas em períodos transitórios. Se o expediente de devolver recursos para os investidores via programa de recompras for alto em determinado período, o modelo de crescimento dos dividendos tende a subestimar o retorno esperado. Fama e French (2002) destaca que o modelo de crescimento de lucro é superior ao modelo de dividendos para estimar o retorno esperado de curto-prazo. Além disso, eles destacam que o modelo de dividendos é melhor no longo-prazo.

Para implementar esta abordagem, extraímos a série de dividend yield fornecida pelo Economática para os tickers elegíveis. Em relação às estimativas da taxa de crescimento dos dividendos e lucros, usamos aquelas calculadas nas seções anteriores, ou seja, 10.3\% e 13.5\%, respectivamente. Os resultados dessa metodologia estão apresentados na tabela 13 abaixo. Pelos argumentos apresentados pelos autores, o prêmio gerado via crescimento dos dividendos e o 
prêmio gerado via crescimento dos lucros deveria ajudar-nos a definir um intervalo para a estimativa do prêmio de risco. Desta forma, esta metodologia sugere que o prêmio de risco para 2015 estaria entre $0.4 \%$ e $3.6 \%$.

Tabela 13 - Modelo de Fama e French

\begin{tabular}{ccccccc}
\hline & Swap & Dividend Yield & $\mathbf{E}(\mathbf{R})_{\mathbf{D}}$ & $\mathbf{E}(\mathbf{R})_{\mathbf{L}}$ & Prêmio $_{\mathbf{D}}$ & Prêmio $_{\mathbf{L}}$ \\
\hline 2012 & $16.4 \%$ & $5.35 \%$ & $15.7 \%$ & $18.9 \%$ & $-0.8 \%$ & $2.4 \%$ \\
2013 & $15.9 \%$ & $5.27 \%$ & $15.6 \%$ & $18.8 \%$ & $-0.3 \%$ & $2.9 \%$ \\
2014 & $15.3 \%$ & $5.17 \%$ & $15.5 \%$ & $18.7 \%$ & $0.2 \%$ & $3.4 \%$ \\
2015 & $15.0 \%$ & $5.11 \%$ & $15.4 \%$ & $18.6 \%$ & $0.4 \%$ & $3.6 \%$ \\
\hline
\end{tabular}

Nota: Swap representa a média da taxa referencial de swaps, ou seja, de 1999 até o ano referido. Da mesma forma, $D_{t} / P_{t-1}$ representa o dividend yield médio do período. $E(R)_{D}$ representa o retorno esperado usando a taxa de crescimento média do dividendo $g_{D} . E(R)_{L}$ representa o retorno esperado usando a taxa de crescimento média do lucro $g_{L}$.

\subsection{SURVEYS}

Esta abordagem consiste em mandar um e-mail para professores, analistas e gestores perguntando qual estimativa do ERP eles estão usando naquele ano. Assim, dado que o preço das ações é determinado pela oferta e demanda dos investidores, esta metodologia deveria apresentar alguma capacidade de previsão do ERP. Fernandez et al (2015b) apresenta as estatísticas de pesquisas questionando o ERP requerido que foram implementados em vários anos e em diversos países. A tabela 14 abaixo apresenta os resultados do ERP para o Brasil.

Tabela 14 - Prêmio de Risco de Mercado de Surveys

\begin{tabular}{|c|c|c|c|}
\hline & ERP & Mediana & Desvio Padrão \\
\hline 2012 & $7.9 \%$ & $7.0 \%$ & $4.7 \%$ \\
\hline 2013 & $6.5 \%$ & $6.0 \%$ & $2.1 \%$ \\
\hline 2014 & $7.8 \%$ & $7.0 \%$ & $4.2 \%$ \\
\hline 2015 & $7.5 \%$ & $5.2 \%$ & $2.1 \%$ \\
\hline
\end{tabular}




\section{EXTENSÕES AOS MODELOS PROPOSTOS PELA LITERATURA}

Apresentamos nas seções anteriores os resultados de algumas metodologias usadas para inferir o prêmio de risco esperado sugeridas pela literatura. Nas próximas páginas, propomos duas extensões possíveis de serem feitas aos modelos dividendos descontados.

\subsection{DIVIDENDOS COM SUAVIZAÇÃO EWMA}

No Modelo de Gordon apresentado, trabalhamos com a hipótese que o investidor leva em consideração a taxa média de crescimento anual dos dividendos para inferir o futuro fluxo de caixa. Nesta seção, nossa proposta é que o investidor leva em consideração informação do crescimento dos dividendos de longo prazo e de curto prazo. Desta forma, podemos trabalhar com o Modelo de Gordon de uma forma diferente, ou seja, calculando uma taxa de crescimento que varia no tempo. Isto é, se o crescimento dos dividendos tem apresentado um crescimento sistemático, uma queda durante um determinado ano deveria afetar pouco a expectativa do investidor em relação à evolução futura dos dividendos. Logo, podemos considerar que ele dê um peso maior para o crescimento de longo prazo e um peso menor para o de curto prazo. Para realizar essa ponderação, podemos usar a Média Móvel Ponderada Exponencialmente (também conhecida na literatura como EWMA). O EWMA é uma técnica muito usada de suavização, a série suavizada $x_{t}$ é obtida da seguinte forma:

$$
x_{t}=\alpha g_{t}+\alpha(1-\alpha) g_{t-1}+\alpha(1-\alpha)^{2} g_{t-2}+\alpha(1-\alpha)^{3} g_{t-3}+\cdots
$$

Podemos reescrever como:

$$
x_{t}=\alpha g_{t}+(1-\alpha) x_{t-1}
$$

Dando um peso de $\alpha=0.25$ para cada informação nova de dividendos e consequentemente um peso de $(1-\alpha)=0.75$ para os dividendos suavizados dos meses anteriores, chegamos aos resultados apresentados na tabela 15 abaixo. Note que, por meio desta metodologia, chegamos num $g$ que varia consideravelmente no tempo. 
Tabela 15 - Dividendos com suavização EWMA

\begin{tabular}{cccccc}
\hline & D/P & g & Retorno Esperado & Swap & Prêmio \\
\hline 2012 & $4.6 \%$ & $14.8 \%$ & $20.1 \%$ & $10.0 \%$ & $10.1 \%$ \\
2013 & $3.9 \%$ & $7.2 \%$ & $11.4 \%$ & $7.1 \%$ & $4.3 \%$ \\
2014 & $3.8 \%$ & $4.3 \%$ & $8.3 \%$ & $10.6 \%$ & $-2.3 \%$ \\
2015 & $4.9 \%$ & $10.6 \%$ & $16.0 \%$ & $13.0 \%$ & $3.0 \%$ \\
\hline
\end{tabular}

\subsection{PREVISÃO DOS DIVIDENDOS}

Nos Modelos de Dividendos Descontados apresentados nas seções anteriores, os investidores estão olhando para os dados realizados de dividendos, lucros e retornos sobre o patrimônio para inferir o futuro. Basicamente, no Modelo de Gordon padrão e no Modelo com recompras, eles olham para a taxa média de crescimento histórica dos dividendos e supõe que irá refletir o comportamento futuro. Nesta seção, nossa proposta é usar modelos univariados de previsão para estimar o $g$ do Modelo de Gordon variando no tempo. Para isso, usaremos a estrutura dos modelos ARIMA para projetar os dividendos de um ano à frente. Vale ressaltar que, conforme destacado por Duarte e Rosa (2013), a inclusão de expectativa futura deveria capturar melhor a natureza forward-looking dos Modelos de Dividendos Descontados. Por meio da metodologia de Box e Jenkins (1970), estimamos a taxa de crescimento dos dividendos e chegamos aos valores apresentados pela tabela abaixo.

Tabela 16 - Previsão com ARIMA

\begin{tabular}{cccc}
\hline & $g$ & Retorno Esperado & Prêmio \\
\hline 2012 & $23 \%$ & $28.3 \%$ & $18.3 \%$ \\
2013 & $-15 \%$ & $-12.0 \%$ & $-19.1 \%$ \\
2014 & $-4 \%$ & $-0.5 \%$ & $-11.1 \%$ \\
2015 & $34 \%$ & $40.9 \%$ & $27.9 \%$ \\
\hline
\end{tabular}




\section{TESTANDO OS MODELOS}

Nas páginas anteriores apresentamos vários modelos e variáveis preditivas sugeridas pela literatura de estimação do prêmio de risco. Um fato que decorre diretamente da implementação de tais modelos refere-se à heterogeneidade dos resultados encontrados. De forma semelhante, Fernandez (2015a) faz uma revisão dos artigos sobre o tema e sua principal constatação é que existe um alto grau de variabilidade dos valores encontrados pelas abordagens que estimaram o prêmio de risco americano. Entretanto, existe um significativo esforço no desenvolvimento de testes estatísticos mais apurados para verificar o poder explicativo dos modelos propostos. Se por um lado, muitos dos estudos existentes focam nos testes in-sample e concluem que existe significante evidência de previsibilidade do prêmio. Por outro, conforme documentou Goyal e Welch (2008), os resultados out-sample podem apresentar inexistência de previsibilidade. Consequentemente, testes de previsão fora da amostra passaram a receber muita atenção da literatura recente (SPIEGEL, 2008).

Nas próximas seções, aplicaremos testes fora da amostra para verificar o desempenho dos modelos sugeridos em relação à previsibilidade do prêmio histórico. Em outras palavras, verificaremos se os modelos apresentados forneceram informações úteis para os investidores em suas decisões de investimento. Primeiramente, testaremos o prêmio de curto prazo e, em seguida, estenderemos a análise para o prêmio de médio e longo prazo. Por fim, investigamos se a combinação das informações dos modelos individuais pode melhorar a previsibilidade.

\subsection{PRÊMIO DE CURTO PRAZO}

Campbell (2007) destaca que o teste fundamental para qualquer modelo preditivo de prêmio de risco é seu desempenho fora da amostra. Para realizar este tipo de teste nos modelos e variáveis apresentados neste trabalho, primeiramente, realizamos a estimação do modelo padrão de regressão do prêmio de risco:

$$
r_{t+1}^{e}=\alpha_{i}+\beta_{i} x_{i, t}+\epsilon_{t+1}
$$


Onde $r_{t+1}^{e}$ representa o excesso de retorno, $x_{i, t}$ é a variável ou modelo $i$ cujo poder preditivo queremos testar e $\epsilon_{t+1}$ é o termo de erro. Assim, rodamos a regressão acima recursivamente em toda janela que queremos realizar a previsão. Em outros termos, dividimos a amostra total de $T$ observações em duas partes. As primeiras $m$ observações correspondem ao conjunto de dados que usaremos para realizar a estimação e as últimas $q=T-m$ observações corresponde à janela que iremos prever. A primeira previsão fora da amostra do prêmio de risco é dada por:

$$
\hat{r}_{i, m+1}^{e}=\hat{\alpha}_{i, m}+\hat{\beta}_{i, m} x_{i, m}
$$

Onde $\hat{\alpha}_{i, m}$ e $\hat{\beta}_{i, m}$ são estimados por mínimos quadrados ordinários usando observações de 1 a $m$. A segunda previsão fora da amostra é gerada por:

$$
\hat{r}_{i, m+2}^{e}=\hat{\alpha}_{i, m+1}+\hat{\beta}_{i, m+1} x_{i, m+1}
$$

Desta forma, repetindo o processo acima iterativamente, geramos uma série com $q$ previsões do prêmio fora da amostra. Note que, a cada observação acrescentada em $m$, realizamos uma nova estimação e obtemos novos valores para os parâmetros $\hat{\alpha}$ e $\hat{\beta}$. Este procedimento fornece no final do período de previsão uma série de tempo dos retornos previstos $\left\{\hat{r}_{i, t+1}\right\}_{t=m}^{T-1}$. Assim, estamos simulando uma situação de previsão em tempo real, onde o investidor teria que inferir por meio do conjunto de informação em cada período do tempo o prêmio de risco do próximo período.

A média histórica do prêmio de risco é representada por $\bar{r}_{t+1}=\sum_{j=1}^{t} r_{j}^{e}$. Intuitivamente, se a variável preditiva contém informação útil para estimar o prêmio de risco, ela deveria possuir uma capacidade de previsão maior que a média histórica. Em outras palavras, $\hat{r}_{i, t+1}$ deveria estar mais próximo de $r_{t+1}^{e}$. Seguindo esta lógica, apresentamos duas propostas da literatura. A primeira baseia-se em Goyal e Welch (2008) e consiste em calcular o valor absoluto da diferença entre a raiz do erro quadrático médio de previsão do prêmio histórico relativo ao modelo preditivo:

$$
\Delta R M S E=\sqrt{\frac{1}{q} \sum_{k=1}^{q}\left(r_{m+k}-\bar{r}_{m+k}\right)^{2}}-\sqrt{\frac{1}{q} \sum_{k=1}^{q}\left(r_{m+k}-\hat{r}_{i, m+k}\right)^{2}}
$$


Onde um $\triangle R M S E>0$ indica que o modelo preditivo apresentou um desempenho superior ao prêmio histórico. Entretanto, a proposta que tem recebido mais atenção da literatura refere-se à sugerida por Campbell e Thompson (2008). Eles propuseram a seguinte estatística $R^{2}$ fora da amostra:

$$
R_{O S}^{2}=1-\frac{\sum_{k=1}^{q}\left(r_{m+k}-\hat{r}_{i, m+k}\right)^{2}}{\sum_{k=1}^{q}\left(r_{m+k}-\bar{r}_{m+k}\right)^{2}}
$$

A estatística $R_{O S}^{2}$ fora da amostra mensura a redução do erro quadrático do modelo preditivo em relação à média histórica. Quando $R_{O S}^{2}>0$, temos que o desempenho de previsão do modelo preditivo foi superior ao do prêmio histórico. Além de calcular a magnitude desta estatística, também testamos se o valor encontrado pelo $R_{O S}^{2}$ é relevante, ou seja, verificamos se a superioridade no desempenho preditivo de determinado modelo é estatisticamente significante. Para isso, uma possibilidade seria usar o tradicional método do Diebold e Mariano (1995). No entanto, estamos trabalhando com um modelo aninhado, ou seja, considerando que $\beta_{i}=0$, temos que a constante representa o prêmio histórico. Desta forma, tal metodologia não séria um método de inferência válido. Para modelos aninhados, Clark e West (2007) desenvolveram uma versão da estatística do Diebold e Mariano (1995) que eles denominaram de erro quadrático médio de previsão ajustado (MSPE - adjusted statistic). Para estima-la, primeiramente, calculamos a seguinte série:

$$
f_{t+1}=\left(r_{t+1}-\bar{r}_{t+1}\right)^{2}-\left[\left(r_{t+1}-\hat{r}_{t+1}\right)^{2}-\left(\bar{r}_{t+1}-\hat{r}_{t+1}\right)^{2}\right]
$$

Chegamos à estatística do $M S P E$ - adjusted statistic regredindo a série $f_{t+1}$ numa constante e calculando a estatística $t$. Deste modo, podemos testar formalmente se a regressão usando informação da variável preditiva $x_{i}$ é estatisticamente significante testando a nula de $R_{O S}^{2} \leq 0$ contra a alternativa $R_{O S}^{2}>0$. Além da significância estatística, também podemos verificar se tais modelos apresentaram significância econômica para os investidores seguindo a proposta que foi usada por Campbell e Thompson (2008), Li, Ng e Swaminathan (2013), Marquering e Verbeek (2004) e Wachter e Warusawitharana (2009). Para isso, consideramos um investidor com preferência média-variância que procura otimizar o seguinte problema: 


$$
\max _{w_{t}} u\left(E_{t}\left\{r_{p, t+1}\right\}, \operatorname{Var}_{t}\left\{r_{p, t+1}\right\}\right)=E_{t}\left\{r_{p, t+1}\right\}-\frac{1}{2} \gamma \operatorname{Var}_{t}\left\{r_{p, t+1}\right\}
$$

Onde $\gamma$ representa o coeficiente de aversão ao risco e $r_{p, t+1}$ o retorno do portfolio do investidor:

$$
r_{p, t+1}=r_{f, t+1}+w_{t}\left(r_{m, t+1}-r_{f, t+1}\right)
$$

Tal que $r_{f, t+1}$ representa o ativo livre de risco, $r_{m, t+1}$ o ativo arriscado e $w_{t}$ representa a participação em $t$ dos ativos arriscados na composição da carteira que o investidor escolherá para $t+1$. Resolvendo o problema de maximização chegamos ao peso ótimo:

$$
w_{t}^{*}=\frac{E_{t}\left\{r_{m, t+1}\right\}-r_{f, t+1}}{\gamma \operatorname{Var}_{t}\left\{r_{m, t+1}\right\}}
$$

A equação acima nos diz que se o prêmio esperado aumentar, tudo mais constate, o investidor deve aumentar a participação de ativos arriscados na composição da sua carteira. Para não permitir short-selling e empréstimos, seguimos Marquering e Verbeek (2004) e fizemos a seguinte restrição:

$$
\begin{gathered}
w_{t}^{R}=0 \text { se } w_{t}^{*} \leq 0 \\
w_{t}^{R}=w_{t}^{*} \text { se } 0<w_{t}^{*} \leq 1 \\
w_{t}^{R}=1 \text { se } w_{t}^{*}>1
\end{gathered}
$$

Logo, trazendo para a linguagem do nosso trabalho, o investidor alocará seu portfolio mensalmente entre ação e ativo livre de risco levando em consideração o prêmio de risco esperado. Se ele prevê o prêmio de risco usando a média histórica, decidirá no fim do período $t$ alocar a seguinte parcela do seu portfolio no período $t+1$ em ações:

$$
w_{1, t}=\left(\frac{1}{\gamma}\right)\left(\frac{\bar{r}_{t+1}}{\hat{\sigma}_{t+1}^{2}}\right)
$$

De modo análogo, sua alocação em ações usando a previsão do modelo preditivo será: 


$$
w_{2, t}=\left(\frac{1}{\gamma}\right)\left(\frac{\hat{r}_{i, t+1}}{\hat{\sigma}_{t+1}^{2}}\right)
$$

Consequentemente, o nível de utilidade média do investidor no período fora da amostra baseado na média histórica é:

$$
U_{1}=\mu_{1}-\frac{1}{2} \gamma \hat{\sigma}_{1}^{2}
$$

Onde $\mu_{1}$ e $\hat{\sigma}_{1}^{2}$ corresponde a média amostral e variância do retorno do portfolio fora da amostra formado por meio de $w_{1, t}$. O nível de utilidade média baseado na previsão fora da amostra do modelo preditivo é:

$$
U_{2}=\mu_{2}-\frac{1}{2} \gamma \hat{\sigma}_{2}^{2}
$$

Onde $\mu_{2}$ e $\hat{\sigma}_{2}^{2}$ corresponde a média amostral e variância do retorno do portfólio formado por $w_{2, t}$ sobre o período fora da amostra. Conforme sugerido por Campbell e Thompson (2008) e Li, $\mathrm{Ng}$ e Swaminathan (2013), estimamos $\hat{\sigma}_{t+1}^{2}$ usando a janela móvel de 10 anos de retornos mensais. Por fim, podemos testar se o investidor obteve ganho de utilidade usando o modelo preditivo tomando a diferença:

$$
\Delta U=U_{2}-U_{1}
$$

De tal forma que $\Delta U>0$ na equação acima representa que o investidor obteve ganho econômico ao usar o modelo preditivo. Multiplicamos esta diferença por 1200 para expressar em termos percentuais anuais e reportamos os resultados usando $\gamma=3$. Antes de apresentar os resultados dos testes acima, utilizaremos a proposta de Welch e Goyal (2008) e apresentaremos uma ilustração gráfica da série de tempo da diferença entre o erro quadrático acumulado da previsão do prêmio histórico e da regressão previsora. Este gráfico é informativo no sentido de fornecer uma ilustração visual dos períodos em que o modelo preditivo obteve desempenho superior ou inferior à média histórica. Isto é, quando as curvas dos gráficos sobem, temos que o modelo preditivo obteve desempenho superior ao prêmio histórico. Consequentemente, ocorre o oposto quanto à curva cai. Estes gráficos também permite comparar a altura da curva do fim do período relativamente ao início. De tal 
forma, uma curva mais alta no fim do período de previsão que no inicio significa que o modelo preditivo tem um erro quadrático de previsão menor que o prêmio histórico.

Conforme podemos constatar pelo gráfico 1 abaixo, nenhum modelo obteve um desempenho sistematicamente melhor que o prêmio histórico no período de previsão analisado. Isto é, em todos gráficos presenciamos períodos onde a curva apresentou inclinação negativa. Apesar disso, vários gráficos apresentaram expressivos períodos em que o modelo preditivo obteve desempenho superior a media histórica. Para testar a significância estatística e econômica desses modelos no período de previsão de 2010:1 a 2014:12, calculamos as estatísticas $R_{O S}^{2}, \triangle R M S E$ e $\Delta U$ numa frequência mensal e apresentamos os resultados na tabela 17 abaixo. Conforme podemos verificar por meio desta tabela, os resultados foram variados. Temos que 19 abordagens apresentaram um desempenho preditivo superior ao do prêmio histórico e 5 apresentaram um desempenho inferior. Destas abordagens, tivemos 11 que apresentaram um $R_{O S}^{2}$ positivo e significativamente maior que zero. Cinco abordagens foram estatisticamente significantes a um nível de $5 \%$ e a razão dividendo-preço foi significante a um nível de 1\%. Por fim, a última coluna da tabela aponta que os investidores tiveram um ganho de utilidade ao usar a maioria dos modelos preditivos ${ }^{15}$.

\footnotetext{
${ }^{15}$ Descrevemos no Apêndice A5 a construção das variáveis e de alguns modelos usados.
} 
Gráfico 1 - llustração gráfica do desempenho dos modelos
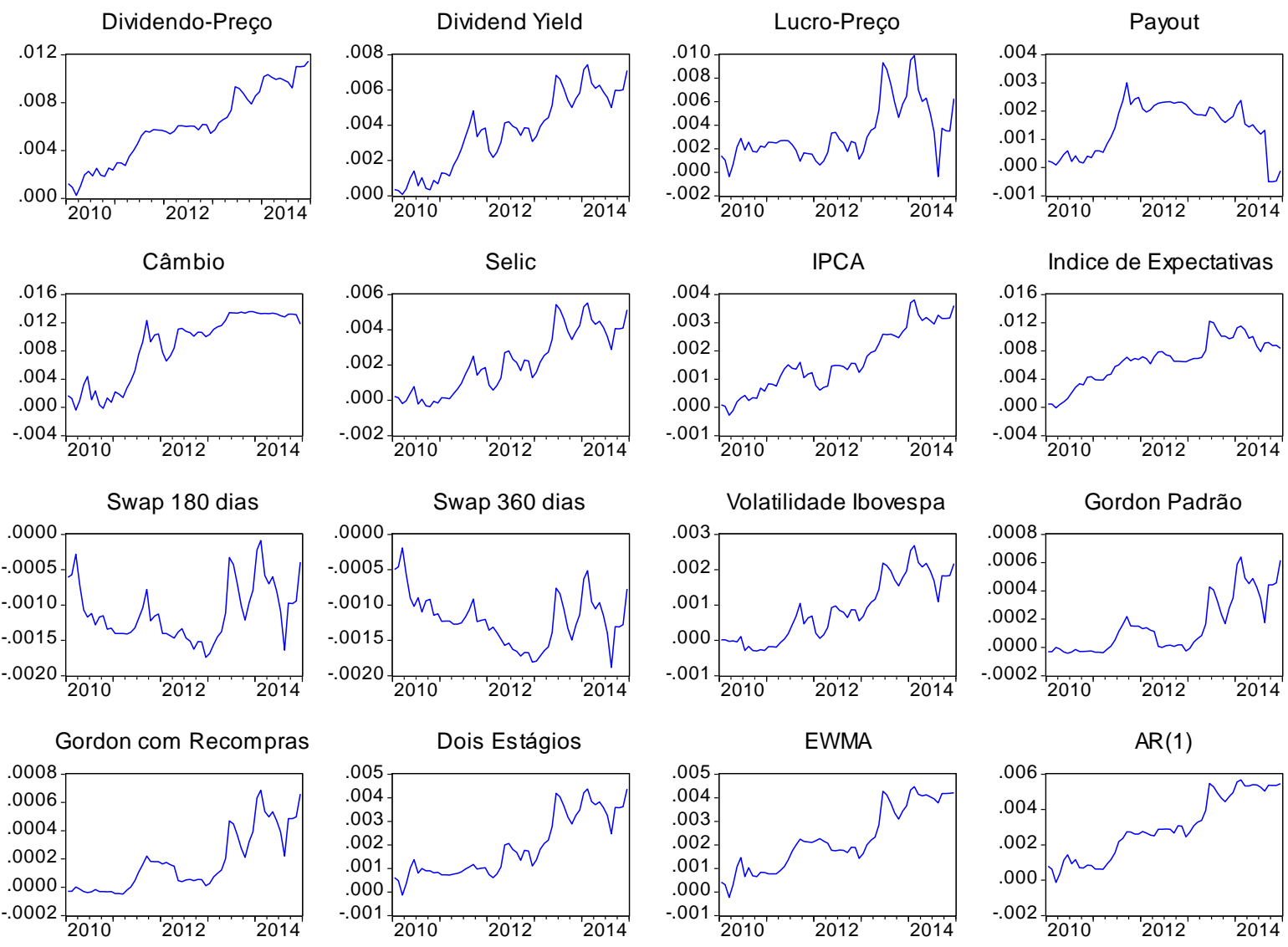

Fama e French - Dividendos
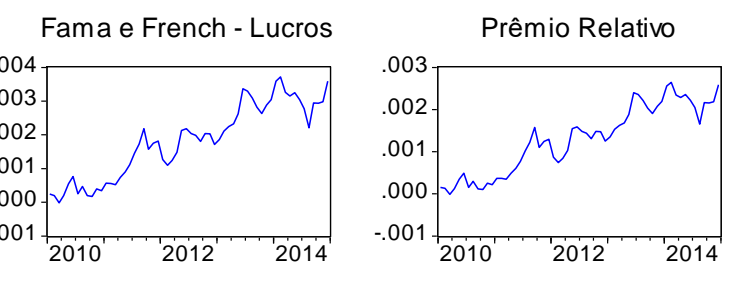

Máxima Verossimilhança
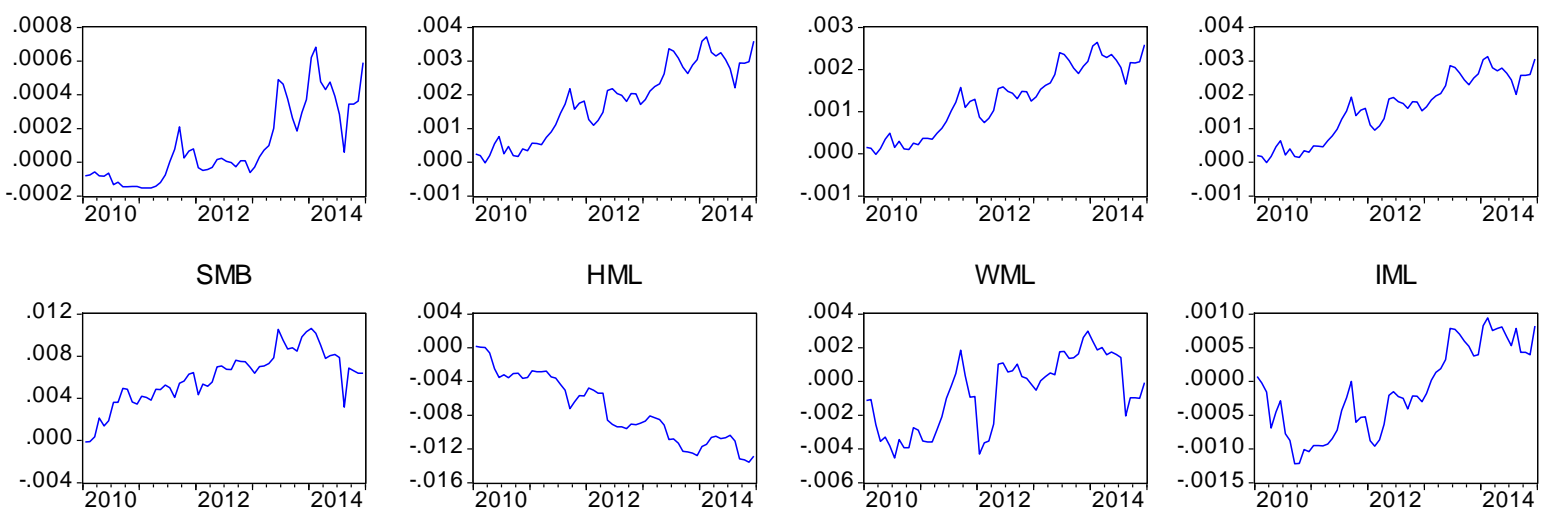

Nota: Os gráficos representam o erro quadrático acumulado da previsão do prêmio histórico menos $o$ erro quadrático acumulado da previsão da regressão previsora. O início da amostra corresponde a 1999:12 e o período de previsão fora da amostra foi de 2010:1-2014:12. 
Tabela 17 - Previsão do prêmio fora da amostra

\begin{tabular}{|c|c|c|c|c|c|}
\hline & $R_{O S}^{2}$ & $\Delta R M S E$ & $M S P E_{\text {adjusted }}$ & $p-$ valor & $\Delta \boldsymbol{U}$ \\
\hline Dividendo-preço & 0.0634 & 0.0018 & 3.11 & $0.00^{\star \star \star}$ & $6.90 \%$ \\
\hline Dividend yield & 0.0393 & 0.0011 & 1.96 & $0.05^{\star *}$ & $7.27 \%$ \\
\hline Lucro-preço & 0.0346 & 0.0010 & 1.49 & 0.14 & $3.25 \%$ \\
\hline Payout & -0.0007 & 0.0000 & 0.11 & 0.92 & $2.16 \%$ \\
\hline Câmbio & 0.0653 & 0.0018 & 2.06 & $0.04^{* *}$ & $5.49 \%$ \\
\hline Selic & 0.0284 & 0.0008 & 1.55 & 0.13 & $6.35 \%$ \\
\hline IPCA & 0.0199 & 0.0006 & 2.05 & $0.04^{\star \star}$ & $3.86 \%$ \\
\hline Índice de Expectativas (IEC) & 0.0462 & 0.0013 & 1.99 & $0.05^{* *}$ & $8.69 \%$ \\
\hline Swap - 180 dias & -0.0022 & -0.0001 & -0.01 & 0.99 & $1.18 \%$ \\
\hline Swap - 360 dias & -0.0043 & -0.0001 & -0.28 & 0.78 & $0.23 \%$ \\
\hline Volatilidade Ibovespa & 0.0120 & 0.0003 & 1.21 & 0.23 & $4.54 \%$ \\
\hline Gordon & 0.0034 & 0.0001 & 1.06 & 0.30 & $1.82 \%$ \\
\hline Gordon com Recompras & 0.0036 & 0.0001 & 1.13 & 0.26 & $1.93 \%$ \\
\hline Dois Estágios de Crescimento & 0.0242 & 0.0007 & 1.64 & 0.11 & $4.05 \%$ \\
\hline EWMA & 0.0233 & 0.0006 & 1.82 & $0.07^{*}$ & $6.35 \%$ \\
\hline $\operatorname{AR}(1)$ & 0.0302 & 0.0008 & 2.20 & $0.03^{\star *}$ & $7.42 \%$ \\
\hline Fama e French - Dividendos & 0.0033 & 0.0001 & 0.84 & 0.40 & $2.04 \%$ \\
\hline Fama e French - Lucros & 0.0198 & 0.0005 & 1.73 & $0.09^{*}$ & $6.14 \%$ \\
\hline Prêmio relativo & 0.0143 & 0.0004 & 1.69 & $0.10^{*}$ & $5.17 \%$ \\
\hline Máxima Verossimilhança & 0.0169 & 0.0005 & 1.75 & $0.09^{*}$ & $5.79 \%$ \\
\hline SMB & 0.0353 & 0.0010 & 1.75 & $0.10^{*}$ & $6.39 \%$ \\
\hline HML & -0.0710 & -0.0019 & -1.10 & 0.29 & $-8.21 \%$ \\
\hline WML & -0.0004 & 0.0000 & -0.30 & 0.77 & $1.12 \%$ \\
\hline IML & 0.0045 & 0.0001 & -0.86 & 0.41 & $2.91 \%$ \\
\hline \multicolumn{6}{|c|}{ 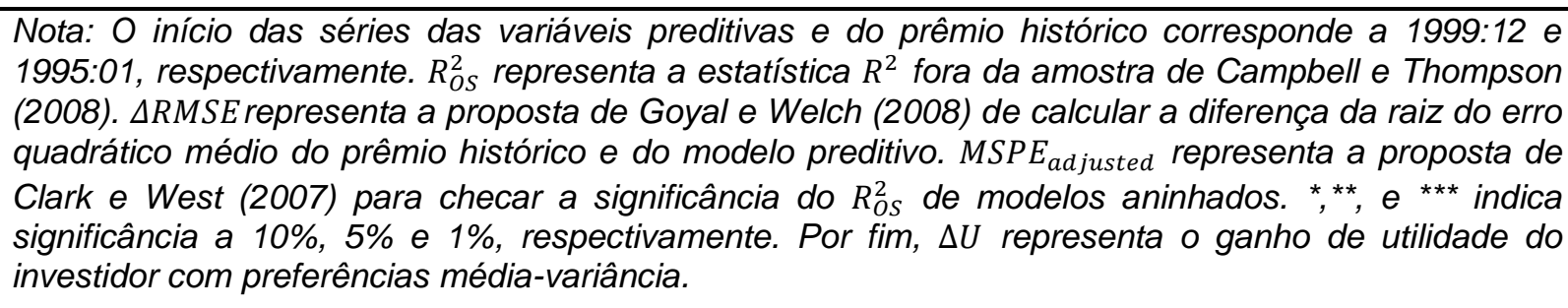 } \\
\hline
\end{tabular}




\subsection{PRÊMIO DE MÉDIO E LONGO PRAZO}

A literatura destaca que a previsibilidade do prêmio tende a aumentar no longo prazo. Se olharmos para construção de alguns modelos, devíamos esperar que seus desempenhos na explicação do prêmio de risco futuro fossem relativamente superiores considerando um prêmio de médio e longo prazo. Por exemplo, no Modelo de Gordon e no Fama e French (2002) temos a hipótese de que usar a taxa de média de crescimento passado dos dividendos e do lucro ajudaria inferir o prêmio de risco futuro. Devido a isto, não seria razoável testar tais modelos usando como variável explicada o prêmio do mês seguinte. Isto porque, a convergência dos prêmios futuros para o prêmio estimado poderá levar um tempo. Com este intuito, seguimos a metodologia de $\mathrm{Li}, \mathrm{Ng}$ e Swminathan (2013) e estimamos a regressão padrão com o prêmio médio de k-períodos futuros como variável dependente regredida em previsores individuais no tempo $t$ :

$$
\sum_{k=1}^{K} \frac{r_{t, t+k}^{e}}{K}=\alpha_{i}+\beta_{i} x_{i, t}+\epsilon_{t+k}
$$

Onde $k$ é o horizonte de previsão do prêmio e $x_{i, t}$ é a variável previsora. O prêmio médio de k-períodos é calculado como a soma cumulativa dos excessos de retornos mensais dividido pelo horizonte de previsão e as regressões foram estimadas considerando $k=12$, 36 e 60 meses. Realizamos este procedimento e reportamos as estatísticas $R_{O S}^{2}$ e $\triangle R M S E$ das abordagens para os diferentes kperíodos futuros do prêmio na tabela 18 abaixo. 
Tabela 18 - Teste para a previsibilidade de médio e longo prazo

\begin{tabular}{l|cc|cc|cc}
\hline & \multicolumn{2}{|c|}{$\mathrm{k}=12$} & \multicolumn{2}{c|}{$\mathrm{k}=36$} & \multicolumn{2}{c}{$\mathrm{k}=60$} \\
& $R_{O S}^{2}$ & $\Delta R M S E$ & $R_{O S}^{2}$ & $\Delta R M S E$ & $R_{O S}^{2}$ & $\Delta R M S E$ \\
\hline Dividendo-preço & 0.3064 & 0.003 & 0.4216 & 0.003 & 0.6419 & 0.003 \\
Dividend yield & 0.1801 & 0.002 & 0.4045 & 0.003 & 0.2643 & 0.001 \\
Lucro - preço & 0.2703 & 0.003 & 0.3881 & 0.003 & 0.2088 & 0.001 \\
Payout & 0.0160 & 0.000 & 0.0592 & 0.000 & 0.0465 & 0.000 \\
Câmbio & 0.4197 & 0.004 & 0.8199 & 0.007 & 0.7380 & 0.004 \\
Selic & 0.2434 & 0.002 & 0.7310 & 0.006 & 0.8387 & 0.005 \\
IPCA & 0.1133 & 0.001 & 0.0813 & 0.001 & 0.1039 & 0.000 \\
IEC & 0.1383 & 0.001 & 0.0225 & 0.000 & -0.1301 & -0.001 \\
Swap - 180 dias & 0.2558 & 0.002 & 0.6762 & 0.005 & 0.8857 & 0.006 \\
Swap - 360 dias & 0.2639 & 0.003 & 0.6147 & 0.004 & 0.8240 & 0.005 \\
Volatilidade & 0.3783 & 0.004 & 0.0566 & 0.000 & -0.1625 & -0.001 \\
Gordon & 0.0264 & 0.000 & -0.1479 & -0.001 & -0.1660 & -0.001 \\
Gordon Recompras & 0.0274 & 0.000 & -0.1476 & -0.001 & -0.1663 & -0.001 \\
Dois Estágios & -0.1589 & -0.001 & -0.0227 & 0.000 & -0.2756 & -0.001 \\
EWMA & 0.1791 & 0.002 & -0.0762 & 0.000 & -0.2382 & -0.001 \\
AR(1) & 0.1336 & 0.001 & 0.0233 & 0.000 & -0.1643 & -0.001 \\
Fama - Dividendos & 0.0287 & 0.000 & -0.1606 & -0.001 & -0.2036 & -0.001 \\
Fama - Lucros & 0.1699 & 0.002 & 0.2332 & 0.001 & 0.0055 & 0.000 \\
Prêmio relativo & 0.1254 & 0.001 & -2223 & -0.530 & -1183 & -0.277 \\
SMB & 0.0137 & 0.000 & -0.0018 & -0.335 & -0.2742 & -0.001 \\
HML & -0.0056 & 0.000 & -0.0016 & -0.305 & -0.2382 & -0.001 \\
WML & 0.0338 & 0.000 & -0.0018 & -0.328 & -0.2564 & -0.001 \\
IML & 0.0172 & 0.000 & -0.0017 & -0.328 & -0.2391 & -0.001 \\
\hline NML O O
\end{tabular}

Nota: O inicio da amostra corresponde a 1999:12 e o período de previsão fora da amostra para $k=12$, $k=36$ e k=60 corresponde a 2009:1-2013:12, 2007:1-2011:12 e 2005:1-2009:12, respectivamente. Desta forma, o período de previsão corresponde à janela dos 60 pontos amostrais mais recentes para todos os modelos.

Por meio da tabela acima, constatamos que as variáveis com maiores poder preditivo para o prêmio médio dos próximos 12 meses foram câmbio, volatilidade do Ibovespa, dividendo-preço e lucro-preço, respectivamente. Para a dinâmica de 36 meses temos câmbio, Selic, Swap e dividendo-preço. Já para o prêmio médio de 60 meses temos Swap, Selic, câmbio e dividendo-preço. Desta forma, o principal resultado elucidado por meio desta tabela é que o desempenho na previsibilidade do prêmio de risco de vários modelos e variáveis aumentaram quando consideramos o prêmio futuro de médio e longo prazo. Além disso, vale observar que variáveis macroeconômicas tiveram melhor desempenho na explicação do prêmio de longo-prazo e que variáveis financeiras desempenharam 
melhor no curto-prazo. Entretanto, a melhora na previsibilidade não foi unanime entre os modelos. Por exemplo, o Modelo de Gordon com o crescimento dos dividendos estimados usando um modelo $A R(1)$ obteve um desempenho para $k=12$ relativamente melhor que para $k=1$. Porém, seu poder preditivo para $k=60$ foi inferior ao prêmio histórico. Este fato está de acordo com a literatura e evidência que o poder explicativo das variáveis e modelos varia de acordo com o horizonte do prêmio futuro.

Além dos modelos preditivos analisados na tabela acima, também verificamos o poder preditivo da média histórica de curto prazo, pois conforme discutimos anteriormente, a média histórica de curto prazo pode ser mais informativa que a de longo-prazo. Desta forma, podemos usar a mesma metodologia descrita acima para testar seu poder preditivo. Realizamos este procedimento usando diferentes janelas para estimar a média histórica e apresentamos os resultados na tabela 19 abaixo.

Tabela 19 - Testando o poder preditivo da média histórica de curto prazo

\begin{tabular}{ccc|ccc|ccc}
\hline $\mathrm{k}=12$ & $\boldsymbol{R}_{\boldsymbol{O}}^{2}$ & $\boldsymbol{\Delta R M S E}$ & $\mathrm{k}=36$ & $\boldsymbol{R}_{\boldsymbol{O} S}^{2}$ & $\boldsymbol{\Delta R M S E}$ & $\mathrm{k}=60$ & $\boldsymbol{R}_{\boldsymbol{O}}^{2}$ & $\boldsymbol{\Delta R M S E}$ \\
\hline$(1)$ & & & $(2)$ & & & $(3)$ & & \\
3 & 0.11 & 0.001 & 12 & 0.00 & 0.000 & 12 & -0.18 & -0.0007 \\
6 & 0.15 & 0.001 & 24 & 0.00 & 0.000 & 24 & -0.10 & -0.0004 \\
12 & 0.16 & 0.002 & 36 & -0.03 & 0.000 & 36 & 0.18 & 0.0008 \\
24 & 0.01 & 0.000 & 48 & -0.05 & 0.000 & 48 & 0.51 & 0.0025 \\
36 & -0.09 & -0.001 & 60 & 0.14 & 0.001 & 60 & 0.66 & 0.0035 \\
48 & 0.05 & 0.000 & 72 & 0.40 & 0.003 & 72 & 0.71 & 0.0038 \\
60 & -0.39 & -0.003 & 84 & 0.67 & 0.005 & 84 & 0.46 & 0.0022 \\
72 & -0.41 & -0.003 & 96 & 0.66 & 0.005 & 96 & 0.16 & 0.0007 \\
\hline
\end{tabular}

Nota: As colunas (1), (2) e (3) representam a quantidade de meses usada para estimar a média histórica. O período de previsão fora da amostra para k=12, $k=36$ e k=60 corresponde a 2009:12013:12, 2007:1-2011:12 e 2005:1-2009:12, respectivamente.

Por meio da tabela acima, verificamos que o poder preditivo da média de curto prazo supera o do prêmio histórico considerando algumas janelas de média móvel. Assim, na próxima seção, também consideraremos informações da média histórica de curto prazo no momento de combinar informações dos modelos individuais. 


\subsection{COMBINAÇÃO DOS MODELOS INDIVIDUAIS}

Conforme destacamos, diversos autores têm apresentado modelos e variáveis que ajudam a detectar mudanças nas condições econômicas e que poderiam sinalizar flutuações no prêmio de risco esperado. Entretanto, tais variáveis isoladamente podem captar diferentes componentes das condições de negócios. Neste sentido, Rapach, Strauss e Zhou (2010) argumentam que fatores como mudanças institucionais, choques de políticas econômicas, avanços na tecnologia de informação e aprendizado dos investidores podem impactar no processo gerador dos dados do prêmio esperado de tal forma que seria difícil de aproximar usando uma única abordagem. Logo, os autores destacam que uma simples combinação de previsão tal como a média, poderia acompanhar de forma mais confiável movimentos no prêmio de risco. No entanto, apesar do recente aumento do interesse de combinação de previsões na macroeconomia, o uso pela literatura financeira ainda permanece relativamente raro.

A previsão para o prêmio de mercado $r_{t+1}^{e}$ pode ser realizado no tempo $t$ por meio de uma média ponderada de $N$ previsões individuais baseadas em:

$$
\hat{r}_{c, t+1}=\sum_{i=1}^{N} \omega_{i, t} \hat{r}_{i, t+1}
$$

Onde $\left\{\omega_{i, t}\right\}_{i=1}^{N}$ são os pesos para ponderação calculados no tempo $t$. Podemos usar diversas formas de combinação. Como sugerido por Rapach, Strauss e Zhou (2010), empregamos os métodos de combinação da média, mediana e média aparada. A média fixa $\omega_{i, t}$ para $i=1, \ldots, N$. A mediana consiste na mediana de $\left\{\hat{r}_{i, t+1}\right\}_{i=1}^{N}$ e a média aparada consiste em fixar $\omega_{i, t}=0$ para previsões individuais com menores e maiores valores e $\omega_{i, t}=1 /(N-2)$ para o restante das previsões individuais. Outra proposta de combinação refere-se à de Stock e Watson (2004), que consiste em combinar os pesos no tempo $t$ como função do desempenho da previsão histórica dos modelos individuais sobre o período fora da amostra. Para isso, ele propõe o Discount Mean Square Prediction Error (DMSPE): 


$$
\begin{gathered}
\omega_{i, t}=\phi_{i, t}^{-1} / \sum_{j=1}^{N} \phi_{i, t}^{-1} \\
\phi_{i, t}=\sum_{s=m}^{t-1} \theta^{t-1-s}\left(r_{s+1}-\hat{r}_{i . s+1}\right)^{2}
\end{gathered}
$$

Onde $\theta$ é um fator de desconto. O método DMSPE da maior peso para aquela variável preditiva que possui melhor desempenho preditivo sobre o período de previsão. Não existe desconto quando $\theta=1$. No entanto, quando $\theta<1$ o método da um peso maior para o desempenho de previsão recente. Desta forma, assim como Rapach, Strauss e Zhou (2010), consideraremos $\theta=1$ e $\theta=0.9$. Além disso, também testamos se a metodologia do Vetor Autorregressivo (VAR) fornece uma melhora sobre a previsão do modelo individual (CHIN e POLK, 2015). Com este intuito, definimos o vetor das variáveis previsoras de $z_{t}$ e, pela especificação do VAR irrestrito, temos que este vetor segue o seguinte processo autorregressivo:

$$
z_{t}=\phi_{0}+\sum_{i=1}^{p} \phi_{i} z_{t-i}+u_{t}
$$

Onde $z_{t}$ é um vetor $n x 1, \phi_{\mathrm{i}}$ é a matriz $n \times n$ dos coeficientes do VAR e $u_{t}$ é o vetor de choque. Consideramos que o VAR segue um processo autorregressivo de primeira ordem e, assim como fizemos nos modelos estimados por MQO acima, estimamos o $\operatorname{VAR}(1)$ recursivamente.

Por fim, testamos a sugestão do Duarte e Rosa (2013) de usar o modelo de componente principal para combinar informação de diversas abordagens. A análise de componentes principais está associada à ideia da redução da massa de dados com menor perda possível da informação. Para isso, construímos uma matriz $X$ onde as colunas representam os modelos individuais e as linhas seus valores (padronizados) numa frequência mensal. Desta forma, o primeiro componente principal corresponde ao autovetor da matriz de variância e covariância de $X$ associado com o maior autovalor e representa a seguinte combinação linear dos modelos individuais:

$$
P C_{t}=\sum_{i=1}^{n} w_{i} x_{i, t}
$$


Na equação acima, $P C_{t}$ é o primeiro componente principal, $x_{i, t}$ é a variável ou modelo $i, w_{i}$ é o peso que o componente principal desempenha no modelo $i$ e $n$ representa a quantidade de variáveis usadas na combinação. De forma semelhante às metodologias de combinação anteriores, calculamos o modelo de primeiro componente principal recursivamente. Assim, geramos a série com informações de vários modelos e rodamos a regressão abaixo de forma análoga a que fizemos na seção do prêmio de curto prazo:

$$
r_{t+1}^{e}=\alpha_{i}+\beta_{i} P C_{t}+\epsilon_{t+1}
$$

Usamos estas abordagens para combinar informações de até sete variáveis preditivas e chegamos aos resultados apresentados na tabela 20 abaixo. Para estimar as propostas de combinação acima, ordenamos as variáveis preditivas individuais de acordo com as maiores estatísticas $R_{O S}^{2}$. Assim, a segunda coluna da tabela abaixo corresponde à combinação de informações das duas variáveis preditivas individuais que obtiveram o maior poder preditivo no período de previsão fora da amostra. Apresentamos no Apêndice A6 uma tabela que sintetiza a ordenação das variáveis usadas em cada conjunto de combinação. Conforme apresentamos anteriormente, temos que os maiores valores do $\mathrm{R}_{\mathrm{OS}}^{2}$ individual para $\mathrm{k}=1, \mathrm{k}=12, \mathrm{k}=36$ e $\mathrm{k}=60$ foram $0.06525,0.4197,0.8199$ e 0.8857 (tabelas 17 e 18), respectivamente. Pelos resultados apresentados pela tabela abaixo, notamos que 0 poder preditivo da combinação das variáveis oscilam entre as abordagens e entre a janela temporal que estamos prevendo. Para $\mathrm{k}=1$, o melhor resultado que obtivemos em termos de $\mathrm{R}_{\mathrm{OS}}^{2}$ foi o do modelo de componente principal usado para combinar três variáveis preditivas. No entanto, este tipo de combinação apresentou um desempenho preditivo superior ao modelo individual considerando a combinação de qualquer conjunto de variáveis preditivas. No caso da previsão do prêmio médio de 12 meses, o modelo DMSPE $\operatorname{com} \theta=1.0$ apresentou um resultado relativamente próximo ao melhor modelo individual quando consideramos sete variáveis preditivas. Entretanto, quando consideramos duas variáveis preditivas, temos que o resultado apresentado pelo modelo de componente principal foi relativamente maior. Para os prêmios médio de 36 e de 60 meses, o modelo que apresentou melhores resultados foi o $\operatorname{VAR}(1)$. 
Tabela 20 - Combinação das abordagens

\begin{tabular}{|c|c|c|c|c|c|c|}
\hline \multirow[b]{2}{*}{ Número de Variáveis Preditivas } & \multicolumn{6}{|c|}{$R_{O S}^{2}$} \\
\hline & 2 & 3 & 4 & 5 & 6 & 7 \\
\hline \multicolumn{7}{|l|}{$k=1$} \\
\hline Média & 0.0712 & 0.0687 & 0.0623 & 0.0616 & 0.0575 & 0.0536 \\
\hline Mediana & 0.0712 & 0.0625 & 0.0527 & 0.0551 & 0.0511 & 0.0454 \\
\hline Media Aparada & & 0.0625 & 0.0527 & 0.0549 & 0.0506 & 0.0468 \\
\hline DMSPE, $\theta=1.0$ & 0.0630 & 0.0616 & 0.0566 & 0.0555 & 0.0518 & 0.0487 \\
\hline DMSPE, $\theta=0.9$ & 0.0633 & 0.0620 & 0.0569 & 0.0558 & 0.0521 & 0.0490 \\
\hline $\operatorname{VAR}(1)$ & 0.0498 & 0.0791 & 0.0739 & 0.0705 & 0.0665 & 0.0511 \\
\hline Componente Principal & 0.0841 & 0.0912 & 0.0815 & 0.0848 & 0.0869 & 0.0785 \\
\hline \multicolumn{7}{|l|}{$k=12$} \\
\hline Média & 0.4698 & 0.4341 & 0.4082 & 0.3877 & 0.3731 & 0.3685 \\
\hline Mediana & 0.4698 & 0.3779 & 0.3566 & 0.3522 & 0.3570 & 0.3521 \\
\hline Media Aparada & & 0.3779 & 0.3566 & 0.3582 & 0.3473 & 0.3496 \\
\hline DMSPE, $\theta=1.0$ & 0.4947 & 0.4517 & 0.4265 & 0.4199 & 0.4161 & 0.4176 \\
\hline DMSPE, $\theta=0.9$ & 0.4845 & 0.4369 & 0.4115 & 0.4054 & 0.4017 & 0.4024 \\
\hline $\operatorname{VAR}(1)$ & 0.5012 & 0.3486 & 0.3342 & 0.4405 & 0.3404 & 0.3443 \\
\hline Componente Principal & 0.6128 & 0.5322 & 0.5016 & 0.4623 & 0.4157 & 0.3971 \\
\hline \multicolumn{7}{|l|}{$k=36$} \\
\hline Média & 0.8177 & 0.7821 & 0.8068 & 0.7800 & 0.7478 & 0.7159 \\
\hline Mediana & 0.8177 & 0.7319 & 0.7695 & 0.7167 & 0.7241 & 0.6842 \\
\hline Media Aparada & & 0.7319 & 0.7695 & 0.7405 & 0.7213 & 0.6906 \\
\hline DMSPE, $\theta=1.0$ & 0.8243 & 0.7948 & 0.8213 & 0.8022 & 0.7868 & 0.7666 \\
\hline DMSPE, $\theta=0.9$ & 0.7145 & 0.6629 & 0.5753 & 0.5996 & 0.624 & 0.6508 \\
\hline $\operatorname{VAR}(1)$ & 0.8074 & 0.8083 & 0.8531 & 0.8417 & 0.8501 & 0.8266 \\
\hline Componente Principal & 0.8203 & 0.8004 & 0.8015 & 0.7969 & 0.7782 & 0.7496 \\
\hline \multicolumn{7}{|l|}{$k=60$} \\
\hline Média & 0.8837 & 0.8716 & 0.8701 & 0.8709 & 0.8605 & 0.8112 \\
\hline Mediana & 0.8837 & 0.8796 & 0.8696 & 0.8597 & 0.8659 & 0.8212 \\
\hline Media Aparada & & 0.8796 & 0.8696 & 0.8581 & 0.8667 & 0.8452 \\
\hline DMSPE, $\theta=1.0$ & 0.8908 & 0.8786 & 0.8821 & 0.8751 & 0.8790 & 0.8711 \\
\hline DMSPE, $\theta=0.9$ & 0.8851 & 0.8770 & 0.8736 & 0.8703 & 0.8710 & 0.8473 \\
\hline $\operatorname{VAR}(1)$ & 0.8954 & 0.8864 & 0.9371 & 0.9414 & 0.9389 & 0.8691 \\
\hline Componente Principal & 0.8135 & 0.7886 & 0.8024 & 0.8283 & 0.8236 & 0.8092 \\
\hline
\end{tabular}

Nota: O inicio da amostra corresponde a 1999:12. O período de previsão para $k=12, k=36$ e $k=60$ corresponde a 2009:1-2013:12, 2007:1-2011:12 e 2005:1-2009:12, respectivamente. 
Apesar de, em alguns casos, os resultados considerando um conjunto de variáveis preditivas menor que sete terem apresentado uma maior estatística $R_{O S}^{2}$, conforme veremos na próxima seção, a incorporação de informação de um número maior de variáveis tende diminuir a variabilidade da previsão. Além disso, o processo gerador do prêmio é complexo e pode mudar no tempo de tal forma que, variáveis preditivas que ofereceram razoável previsibilidade em determinados períodos do tempo, poderá fornecer piores resultados em outros. Assim, combinar informação de várias variáveis que estão correlacionadas com retornos subsequentes tende acompanhar melhor o ciclo de negócios (RAPACH, STRAUSS e ZHOU, 2010). Neste sentido, note por meio da tabela acima que para o período de previsão de 2005:1 a 2009:12, o modelo de combinação DMSPE com $\theta=1.0$ e $\mathrm{k}=60$ usando duas variáveis preditivas foi superior àquele que usa sete variáveis preditivas. Entretanto, considerando um período de previsão maior, por exemplo, de 2001:01 a 2009:12, temos que a estatística $R_{O S}^{2}$ com duas variáveis foi de 0.80 , enquanto de sete variáveis foi $\mathrm{R}_{\mathrm{OS}}^{2}$ de 0.86 . Com o intuito de apresentar uma ilustração visual para o período compreendido entre 2001:01 a 2009:12 da previsão fora da amostra do modelo de combinação DMSPE (com sete variáveis preditivas) em relação ao modelo do prêmio histórico, apresentamos o gráfico 2 abaixo. Conforme podemos verificar, a previsibilidade do modelo de combinação DMSPE $(\theta=1.0, \mathrm{k}=60)$ foi relativamente superior ao prêmio histórico e, além disso, o modelo conseguiu capturar melhor as flutuações dos prêmios médio futuros. 
Gráfico 2 - Comparação das Previsões

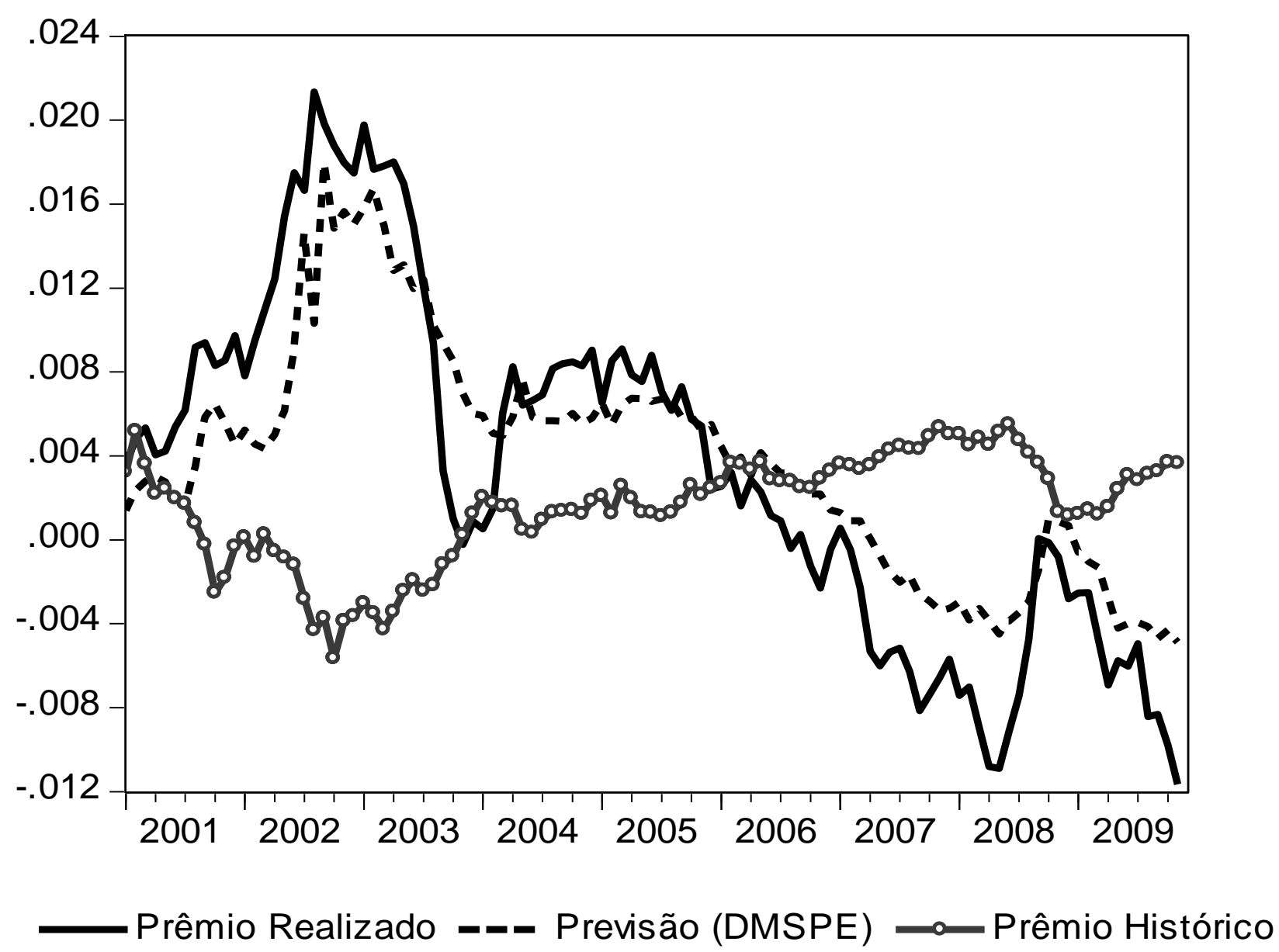




\subsubsection{Estabilização}

Conforme verificamos na seção anterior, se olharmos somente para a estatística $R_{O S}^{2}$, considerando o período de previsão fora da amostra, temos que os resultados foram variados entre o conjunto das variáveis preditivas, sendo que, em alguns casos, a combinação de uma quantidade menor de variáveis preditivas ofereceram uma maior estatística $\mathrm{R}_{\mathrm{OS}}^{2}$. Apesar disso, a combinação de um número maior de variáveis individuais tende a diminuir a variabilidade das previsões. Isso ocorre quando as previsões são fracamente ou negativamente correlacionadas. Conforme podemos verificar por meio da tabela 21 , temos que muitas correlações foram relativamente baixas e até negativas. Como esperado, as correlações entre razões de avaliação foram altas.

Este fato indica que a combinação de previsões poderá diminuir a variabilidade da previsão. Para verificar isto, calculamos a dispersão das previsões dos modelos individuais que apresentaram maior estatística $R_{O S}^{2}$ e da combinação usando a média das previsões na tabela 22 para os diferentes conjuntos de variáveis. Conforme podemos constatar, a variabilidade das previsões dos modelos de combinação foi mais baixa que os modelos individuais. Isso ocorre porque a combinação gera previsões com menores ruídos que o modelo de previsão individual, pois incorpora informação de mais variáveis. Tal fato está de acordo com Rapach, Strauss e Zhou (2010) que destacaram que agregar informações de varias variáveis previsoras tende a ser mais estável e acompanhar melhor as flutuações dos ciclos de negócios. 
Tabela 21 - Matriz de correlação

\begin{tabular}{|c|c|c|c|c|c|c|c|c|c|c|c|c|c|c|c|c|c|c|c|c|c|c|c|c|}
\hline & DP & DY & LP & PY & CM & SL & IA & IE & 180 & 360 & vo & GO & GR & $\mathrm{DE}$ & EW & AR & FFD & FFL & PR & MV & SMB & HML & WML & IML \\
\hline DP & 1.0 & 0.2 & 0.5 & -0.1 & -0.3 & 0.1 & 0.2 & 0.2 & 0.0 & 0.1 & 0.1 & 0.2 & 0.2 & 0.3 & 0.6 & 0.6 & 0.1 & 0.1 & 0.0 & 0.0 & 0.1 & 0.2 & -0.2 & -0.1 \\
\hline DY & 0.2 & 1.0 & 0.5 & 0.6 & -0.6 & 0.8 & 0.7 & 0.4 & 0.9 & 0.9 & 0.8 & 0.9 & 0.9 & 0.6 & 0.5 & 0.4 & 0.9 & 0.8 & 0.8 & 0.9 & 0.3 & 0.3 & 0.1 & 0.6 \\
\hline LP & 0.5 & 0.5 & 1.0 & 0.1 & -0.9 & 0.7 & 0.5 & 0.3 & 0.6 & 0.6 & 0.6 & 0.7 & 0.7 & 0.9 & 0.7 & 0.6 & 0.7 & 0.7 & .6 & 0.7 & 3 & .2 & 0 & 0.3 \\
\hline $\mathrm{CM}$ & -0.3 & -0.6 & -0.9 & -0.3 & 1.0 & -0.7 & -0.6 & -0.2 & -0.7 & -0.8 & -0.7 & -0.8 & -0.8 & -0.8 & -0.5 & -0.4 & -0.8 & -0.8 & -0.8 & -0.8 & -0.4 & -0.3 & -0.1 & -0.4 \\
\hline SL & 0.1 & 0.8 & 0.7 & 0.3 & -0.7 & 1.0 & 0.6 & 0.3 & 0.9 & 0.9 & 0.9 & 0.9 & 0.9 & 0.8 & 0.6 & 0.5 & 0.9 & 0.9 & 0.9 & 0.9 & 0.3 & 0.3 & 0.2 & 0.7 \\
\hline IA & 0.2 & 0.7 & 0.5 & 0.4 & -0.6 & 0.6 & 1.0 & 0.2 & 0.6 & 0.6 & 0.6 & 0.6 & 0.6 & 0.4 & 0.3 & 0.2 & 0.6 & 0.6 & 0.6 & 0.6 & 0.3 & 0.2 & 0.0 & 0.5 \\
\hline 360 & 0.1 & 0.9 & 0.6 & 0.5 & -0.8 & 0.9 & 0.6 & 0.3 & 1.0 & 1.0 & 1.0 & 1.0 & 1.0 & 0.7 & 0.5 & 0.4 & 1.0 & 1.0 & 1.0 & 1.0 & 0.4 & 0.2 & 0.3 & 0.6 \\
\hline vo & 0.1 & 0.8 & 0.6 & 0.5 & -0.7 & 0.9 & 0.6 & 0.3 & 1.0 & 1.0 & 1.0 & 1.0 & 1.0 & 0.7 & 0.5 & 0.4 & 1.0 & 1.0 & 1.0 & 1.0 & 0.4 & 0.2 & 0.2 & 0.6 \\
\hline GO & 0.2 & 0.9 & 0.7 & 0.5 & -0.8 & 0.9 & 0.6 & 0.3 & 1.0 & 1.0 & 1.0 & 1.0 & 1.0 & 0.7 & 0.6 & 0.4 & 1.0 & 1.0 & 1.0 & 1.0 & .4 & .2 & 0.2 & 0.6 \\
\hline GR & 0.2 & 0.9 & 0.7 & 0.5 & -0.8 & 0.9 & 0.6 & 0.3 & 1.0 & 1.0 & 1.0 & 1.0 & 1.0 & 0.7 & 0.6 & 0.5 & 1.0 & 1.0 & 1.0 & 1.0 & 0.4 & 0.2 & 0.2 & 0.6 \\
\hline DE & 0.3 & 0.6 & 0.9 & 0.1 & -0.8 & 0.8 & 0.4 & 0.3 & 0.7 & 0.7 & 0.7 & 0.7 & 0.7 & 1.0 & 0.7 & 0.7 & 0.7 & 0.8 & 0.8 & 0.8 & .2 & 0.2 & .1 & 0.5 \\
\hline PR & 0.0 & 0.8 & 0.6 & 0.5 & -0.8 & 0.9 & 0.6 & 0.3 & 1.0 & 1.0 & 1.0 & 1.0 & 1.0 & 0.8 & 0.5 & 0.4 & 1.0 & 1.0 & 1.0 & 1.0 & 0.4 & 0.2 & 0.2 & 0.6 \\
\hline MV & 0.0 & 0.9 & 0.7 & 0.5 & -0.8 & 0.9 & 0.6 & 0.3 & 1.0 & 1.0 & 1.0 & 1.0 & 1.0 & 0.8 & 0.5 & 0.4 & 1.0 & 1.0 & 1.0 & 1.0 & 0.4 & 0.2 & 0.2 & 0.6 \\
\hline SMB & 0.1 & 0.3 & 0.3 & 0.2 & -0.4 & 0.3 & 0.3 & 0.0 & 0.4 & 0.4 & 0.4 & 0.4 & 0.4 & 0.2 & 0.2 & 0.0 & 0.4 & 0.4 & 0.4 & 0.4 & 1.0 & -0.1 & 0.4 & -0.2 \\
\hline HML & 0.2 & 0.3 & 0.2 & 0.1 & -0.3 & 0.3 & 0.2 & 0.2 & 0.2 & 0.2 & 0.2 & 0.2 & 0.2 & 0.2 & 0.1 & 0.1 & 0.2 & 0.2 & 0.2 & 0.2 & -0.1 & 1.0 & -0.4 & 0.3 \\
\hline WML & -0.2 & 0.1 & 0.0 & 0.1 & -0.1 & 0.2 & 0.0 & 0.0 & 0.3 & 0.3 & 0.2 & 0.2 & 0.2 & 0.1 & 0.0 & -0.1 & 0.2 & 0.2 & 0.2 & 0.2 & 0.4 & -0.4 & 1.0 & 0.0 \\
\hline IML & -0.1 & 0.6 & 0.3 & 0.4 & -0.4 & 0.7 & 0.5 & 0.2 & 0.6 & 0.6 & 0.6 & 0.6 & 0.6 & 0.5 & 0.3 & 0.3 & 0.6 & 0.6 & 0.6 & 0.6 & -0.2 & 0.3 & 0.0 & 1.0 \\
\hline
\end{tabular}

Nota: Matriz de correlação para o prêmio de risco previsto por modelos de regressão com variáveis individuais. $D P=$ dividendo-preço, $D Y=$ dividend yield, $L P=$ lucro-preço, $P Y=$ payout, $C M=$ câmbio, $S L=$ Selic, $I A=I P C A$, IE = Índice de expectativas, $180=S W A P 180,360=S W A P 360$, VO = Volatilidade, GO = Gordon, GR= Gordon com recompras, $D E=$ Dois Estágios de Crescimento, $E W=E W M A, A R=A R(1), F F D=$ Fama e French - Dividendos, FFL $=$ Fama e French - Lucros, PR $=$ Prêmio relativo, MV $=$ Máxima Verossimilhança. O início da amostra corresponde a 1999:12 e o período de previsão fora da amostra foi de 2010:1-2014:12. 
Tabela 22 - Desvio-Padrão da Previsão

\section{Desvio-Padrão}

\begin{tabular}{cccccccc} 
Número de Variáveis Preditivas & 1 & 2 & 3 & 4 & 5 & 6 & 7 \\
\hline $\mathrm{k}=1$ & $0.65 \%$ & $0.31 \%$ & $0.31 \%$ & $0.24 \%$ & $0.24 \%$ & $0.23 \%$ & $0.22 \%$ \\
$\mathrm{k}=12$ & $0.54 \%$ & $0.34 \%$ & $0.29 \%$ & $0.26 \%$ & $0.23 \%$ & $0.21 \%$ & $0.22 \%$ \\
$\mathrm{k}=36$ & $0.40 \%$ & $0.28 \%$ & $0.23 \%$ & $0.30 \%$ & $0.26 \%$ & $0.24 \%$ & $0.21 \%$ \\
$\mathrm{k}=60$ & $0.47 \%$ & $0.49 \%$ & $0.45 \%$ & $0.42 \%$ & $0.43 \%$ & $0.40 \%$ & $0.39 \%$ \\
\hline
\end{tabular}

Nota: A tabela acima apresenta o desvio-padrão do período de previsão de cada conjunto usando a média para realizar a combinação. A segunda coluna representa o desvio-padrão da previsão do modelo individual que usa como variável preditiva aquela que obteve maior $R_{O S}^{2}$. $O$ inicio da amostra corresponde a 1999:12 e o período de previsão fora da amostra para $k=12, k=36$ e $k=60$ corresponde a 2009:1-2013:12, 2007:1-2011:12 e 2005:1-2009:12, respectivamente.

\section{CONSIDERAÇÕES FINAIS}

Neste trabalho, partimos do fato que o prêmio histórico brasileiro calculado usando os retornos realizados dos últimos vinte anos foi relativamente baixo e, assim, procuramos investigar se tal estimativa constitui um valor razoável para inferirmos o futuro comportamento do mercado acionário. Durante anos, tal abordagem foi vista pela literatura como a melhor estimativa para o retorno esperado (CAMPBELL, 2007). Implicitamente tínhamos a suposição que o retorno esperado seria constante no tempo e, consequentemente, o prêmio futuro deveria convergir para a média dos prêmios passados (DAMORADAN, 2013). Entretanto, na década de 1980 começaram a surgir evidências de previsibilidade dos retornos e, em seguida, a literatura passou a questionar se o retorno esperado seria constante no tempo. Assim, um frutífero campo de pesquisa nasceu com o intuito de analisar a variação no tempo do retorno esperado e diversas técnicas de estimação surgiram na literatura (CAMPBELL e THOMPSON, 2008). Cochrane (2011) destaca que o prêmio esperado varia consideravelmente no tempo e que teorias sobre o tema ainda estão na sua infância. Além disso, ele aponta que existem muitas controvérsias no assunto e argumenta que a literatura sobre o tema necessita de uma forte consolidação.

Se por um lado, vários trabalhos focaram nos testes dentro da amostra e concluíram que existe evidência de previsibilidade do prêmio (COCHRANE, 2008; LEWELLEN, 2004). Por outro, Goyal e Welch (2008) apresentaram evidências que as variáveis previsoras com capacidade preditiva dentro da amostra não obtiveram 
desempenho superior ao prêmio histórico fora da amostra. Nesse sentido, uma grande limitação dos testes dentro da amostra é que os parâmetros da regressão de previsão são estimados usando os dados de toda a série de tempo e, portanto, não leva em consideração se a informação estaria disponível contemporaneamente (CHIN e POLK, 2015). Já os testes fora da amostra permitem verificar comparativamente se os modelos sugeridos pela literatura forneceram informações úteis para os investidores em suas decisões de investimento. Consequentemente, testes de previsão fora da amostra passaram a ter significativa atenção da literatura de estimação do prêmio esperado.

Neste cenário, uma corrente da literatura recente destaca que podemos melhorar o poder preditivo combinando informações dos modelos (CHIN e POLK, 2015; DUARTE e ROSA, 2015; RAPACH, STRAUSS e ZHOU, 2010). Temos documentado diversas variáveis e modelos que possuem potencial informação preditiva. Entretanto, a instabilidade econômica torna difícil de aproximar usando um único modelo. Por exemplo, dois modelos individuais podem capturar diferentes componentes das condições de negócios e, assim, um modelo pode oferecer falsos sinais durante certos períodos do tempo. Se os dois modelos forem fracamente correlacionados, a combinação deveria ser menos volátil e seguir melhor os movimentos do prêmio de risco (RAPACH, STRAUSS e ZHOU, 2010).

Assim, estruturamos a metodologia deste trabalho em três etapas. $\mathrm{Na}$ primeira, procuramos selecionar as principais abordagens apresentadas pela literatura com habilidade para inferir o prêmio de risco e verificamos certa heterogeneidade dos resultados. Em seguida, testamos se elas apresentaram um desempenho preditivo no mercado acionário brasileiro superior ao prêmio histórico. Como resultado, encontramos que alguns modelos superaram o poder preditivo da média histórica e que a previsibilidade tende aumentar no longo-prazo. Neste cenário, não seria razoável levar em consideração somente a média histórica dos retornos realizados para inferir o comportamento do retorno esperado. Consequentemente, o último passo da nossa metodologia foi verificar se a combinação da informação dos modelos melhora a capacidade preditiva. Desta forma, encontramos que a combinação tende a melhorar a previsibilidade e fornecer sinais mais estáveis do futuro comportamento do mercado acionário. Esta melhora na previsibilidade deve-se ao fato da combinação atingir o meio termo em relação à 
variabilidade. Por um lado, os modelos de regressão individual tendem a serem muito voláteis para representar mudanças no prêmio esperado. Por outro lado, a média histórica é muito suave, ignorando assim, informação contida em variáveis econômicas que potencialmente afeta o prêmio esperado. 


\section{REFERÊNCIAS BIBLIOGRÁFICAS}

AVDIS, Efstathios; WACHTER, Jessica. (2014) Maximum likelihood estimation of the equity premium. Working paper. NBER.

BANZ, Rolf (1981) The Relationship Between Return and Market Value of Common Stocks. Journal of Financial Economics. 9:1, pp. 3-18.

BASU, Sanjay. (1977) Investment Performance of Common Stocks in Relation to Their Price-Earnings Ratios: A Test of the Efficient Market Hypothesis. Journal of Finance. 12:3, pp. 129-56.

BHANDARI, Laxmi. (1988) Debt/Equity Ratio and Expected Common Stock Returns: Empirical Evidence. Journal of Finance. 43:2, pp. 507-28.

BOX, George; JENKINS, Gwilym (1970). Time Series Analysis: Forecasting and Control. HoldenDay, San Francisco.

CAMPBELL, John. (2007) Estimating the equity premium. Working paper. NBER.

CAMPBELL, John; SHILLER, Robert (1988a). The dividend-price ratio and expectations of future dividends and discount factors. Review of Financial Studies 1, 195-228.

CAMPBELL, John; SHILLER, Robert (1988b). Stock prices, earnings, and expected dividends. Journal of Finance, 43, 661-676.

CAMPBELL, John; THOMPSON, Samuel (2008) Predicting excess stock returns out of sample: can anything beat the historical average?. The Review of Financial Studis 21(4): 1509-1531.

CARHART, Mark. (1997) On persistence in mutual fund performance. The Journal of Finance, vol. 52, n1.

CHIN, Michael; POLK, Christopher (2015) A forecast evaluation of expected equity return measures. Bank of England. Working paper $n^{\circ} 520$.

CLARK, Todd; WEST, Kenneth. (2007). Approximately Normal Tests for Equal Predictive Accuracy in Nested Models. Journal of Econometrics 138:291-311.

COCHRANE, John. (1999) New facts in finance. NBER working paper No. 7169 
COCHRANE, John (2008). The dog that did not bark: a defense of return predictability. The Review of Financial Studies. v21 n4.

COCHRANE, John. (2011). Presidential address: discount rates. The Journal of Finance. Vol. LXVI, n 4. August 2011.

DAMODARAN, Aswath. (2007) Avaliação de empresas. 2ํ. Ed. Pearson Prentice Hall.

DAMODARAN, Aswath. (2013) Equity risk premiums (ERP): Determinants, Estimation and Implications.

DELONG, Bradford; MAGIN, Konstantin (2009) The U.S Equity Return Premium: Past, Present, and Future. Journal of Economic Perspectives. Volume 23, Number 1. Winter 2009. Pag 193-208.

DIEBOLD, Francis; MARIANO, Roberto. (1995). Comparing Predictive Accuracy. Journal of Business and Economic Statistics 13:253-63.

DUARTE, Fernando; ROSA, Carlo. (2013) The equity risk premium: A consensus of models. Federal Reserve Bank of New York.

FAMA, Eugene; FRENCH, Kenneth. (1988) Dividend yields and expected stock returns. Journal of Financial Economics, 22. 3-25.

FAMA, Eugene; FRENCH, Kenneth. (1996) Multifactor explanations of asset pricing anomalies. The Journal of Finance, vol. LI, n1.

FAMA, Eugene; FRENCH, Kenneth. (2002) The equity premium. The Journal of Finance, vol. LVII, n2.

FAMA, Eugene; FRENCH, Kenneth (2004) The capital asset pricing model: theory and evidence. Journal of Economic Perspectives, vol. 18, n13, summer 2004, pag. 25-46.

FAMA, Eugene; MACBETH, James. (1973) Risk return and equilibrium: Empirical tests. Journal of Political Economy 71, 607-636 
FERNANDEZ, Pablo; CAMPO, Javier (2010) Market Risk Premium used in 2010 by Analysts and Companies: a survey with 2.400 answers. IESE Business School.

FERNANDEZ, Pablo (2013) Equity premium: historical, expected required and implied. IESE Business School.

FERNANDEZ, Pablo; LINARES, Pablo; ACIN, Isabel (2014) Market risk premium used in 88 countries in 2014: a survey with 8.228 answers.

FERNANDEZ, Pablo. (2015a) The Equity Premium in 150 textbooks. IESE Business School.

FERNANDEZ, Pablo; ORTIZ, Alberto; ACIN, Isabel (2015b) Discount Rate (RiskFree Rate and Market Risk Premium) used for 41 countries in 2015: a survey. IESE Business School.

GORDON, Myron (1962) The investment, financing and valuation of the corporation. Greenwood Press.

GOYAL, Amit; WELCH, Ivo. (2008) A comprehensive look at the empirical performance of equity premium prediction. The Review of Financial Studies, v21, n4.

HIGGINS, Robert. (1977) How much growth can a firm afford?. Financial Management. Vol. 6, n³. Autumn, 7-16

LEWELLEN, Jonathan (2004). Predicting returns with financial ratios. Journal of Financial Economics 74 209-235

LI, Yan; NG, David; SWAMINATHAN, Bhaskaran (2013). Predicting market returns using aggregate implied cost of capital. Journal of Financial Economics 110. 419436.

LINTNER, John. (1965) The Valuation of Risk Assets and the Selection of Risky Investments in Stock Portfolios and Capital Budgets. Review of Economics and Statistics. 47:1, pp. 13-37. 
MARKOWITZ, Harry. (1959) Portfolio Selection: Efficient Diversification of Investments. Cowles Foundation Monograph No. 16. New York: John Wiley \& Sons, Inc.

MARQUERING, Wessel; VERBEEK, Marno (2004). The economic value of predicting stock index returns and volatility. Journal of Financial and Quantitative Analysis.

MINARDI, Andrea; SANVICENTE, Antônio (2006). Análise da série histórica de prêmios pelo risco de mercado estimados pelo modelo de dividendos descontados. Working paper. Insper.

PÁSTOR, Lubos; STAMBAUGH, Robert. (2001). The equity premium and structural breaks. Journal of Finance, 56(4), 1207-1239.

PENMAN, Stephen. (2001) Financial statement analysis and security valuation. McGraw-Hill.

RAPACH, David; STRAUSS, Jack; ZHOU, Guofu. (2010). Out-of-sample equity premium prediction: combination forecasts and links to the real economy, Review of Financial Studies, 23(2), pp. 821-862

ROZEFF, Michael. (1984) Dividend yields are equity risk premiums. Journal of Portfolio Management, 11(1), 68-75.

SPIEGEL, Matthew (2008) Forecasting the Equity Premium: Where we stand today. The Review of Financial Studies. v21 n4.

SHARPE, William. (1964) Capital Asset Prices: A Theory of Market Equilibrium under Conditions of Risk. Journal of Finance. 19:3, pp. 425-42.

STOCK, James; WATSON, Mark (2004). Combination forecasts of ouput growth in a seven-country data set. Journal of Forecasting. 23, 405-430.

WACHTER, Jessica; WARUSAWITHARANA, Missaka (2009). Predictable returns and asset allocation: Should a skeptical investor time the market? Journal of Econometrics 162-178 


\section{APÊNDICE}

A1 - Tickers Elegíveis

A2 - Taxa de Crescimento dos Lucros

A3 - Tickers Elegíveis para os Modelos de Cross-Section

A4 - Estimação por Máxima Verossimilhança

A5 - Construção das Variáveis e Modelos

A6 - Variáveis Selecionadas na Combinação 
A1- TICKERS ELEGÍVEIS

\begin{tabular}{cccccccc} 
ABCB4 & AGIN3 & AGEI3 & AGEN33 & ALSC3 & ACES4 & AMBV4 & AMIL3 \\
IRON3 & AEDU3 & ANIM3 & ARCZ6 & ARZZ3 & ARTR3 & AUTM3 & BTOW3 \\
BRSR6 & BBSE3 & BMEF3 & BVMF3 & BOVH3 & BBRK3 & BRIN3 & BRML3 \\
BPHA3 & BRPR3 & BBDC3 & BBDC4 & BRAP4 & BBAS3 & BBAS4 & BRTP3 \\
BRTP4 & BRKM5 & BRFS3 & BISA3 & CMET4 & CCRO3 & CCXC3 & CMIG4 \\
CESP6 & CTIP3 & CIEL3 & CGAS5 & CPNY3 & CNFB4 & CSMG3 & CPLE6 \\
CSAN3 & CPFE3 & CRTP5 & CRGT5 & CVCB3 & CYRE3 & DASA3 & DUFB11 \\
DTEX3 & ECOR3 & ELET3 & ELET6 & ELPL4 & EMBR3 & EMBR4 & ENBR3 \\
ENEV3 & EQTL3 & ESTC3 & EVEN3 & EZTC3 & FIBR3 & VCPA4 & FLRY3 \\
GFSA3 & GGBR4 & GOAU4 & GOLL4 & GVTT3 & HRTP3 & HYPE3 & IGTA3 \\
ITSA4 & ITUB4 & JBSS3 & JSLG3 & KLBN4 & KSSA3 & KROT3 & LIGT3 \\
LINX3 & RENT3 & LAME4 & AMAR3 & LREN3 & LPSB3 & LUPA3 & MDIA3 \\
MGLU3 & MAGG3 & MRFG3 & MEDI3 & LEVE3 & MILS3 & BEEF3 & MMXM3 \\
MRVE3 & MULT3 & MPLU3 & NATU3 & NETC4 & BNCA3 & ODPV3 & OGXP3 \\
OIBR4 & OSXB3 & PCAR4 & BPNM4 & PDGR3 & PETR3 & PETR4 & BRDT4 \\
PSSA3 & POSI3 & QGEP3 & QUAL3 & RAIA3 & RADL3 & RDCD3 & SBSP3 \\
SDIA4 & SMTO3 & SEER3 & CSNA3 & CSTB4 & SSBR3 & SLCE3 & SMLE3 \\
CRUZ3 & SUBA3 & TAMM4 & TECN3 & TCSA3 & TGMA3 & TCOC4 & TNEP4 \\
VIVT4 & TNLP3 & TNLP4 & TMAR5 & TMCP4 & TEND3 & TIMP3 & TCSL4 \\
TOTS3 & TRPL4 & UGPA3 & USIM5 & VAGR3 & VALE3 & VALE5 & VLID3 \\
VIVO4 & WEGE3 & WHMT3 & & & & & \\
\hline
\end{tabular}

\section{A2- TAXA DE CRESCIMENTO DOS LUCROS}

Pela taxa de crescimento dos lucros temos:

$$
g_{t}=\frac{L L_{t}-L L_{t-1}}{L L_{t-1}}
$$

Onde $g_{t}$ representa a taxa de crescimento do lucro líquido, $L L_{t}$ representa o lucro líquido no ano $t$. Podemos reescrever a taxa de crescimento dos lucros numa forma alternativa. Para isto, dado a definição do ROE (retorno sobre o patrimônio líquido), o lucro líquido no ano $t-1$ pode ser escrito como:

$$
L L_{t-1}=\text { Patrimônio líquido }{ }_{t-2} x R O E_{t-1}
$$

Então, o lucro líquido pode ser formulado como:

$$
L L_{t}=\left(\text { Patrimônio líquido }_{t-2}+\text { Lucros retidos }_{t-1}\right) x R O E_{t}
$$

Supondo que o ROE não se altere no tempo, temos:

$$
g_{t}=(\text { Razão de retenção })(R O E)
$$




\section{A3 - TICKERS ELEGÍVEIS PARA OS MODELOS DE CROSS-SECTION}

\begin{tabular}{llllllllll}
\hline BBDC3 & BBDC4 & BBAS3 & BRKM5 & CMIG4 & CGAS5 & CPLE6 & ELET3 & ELET6 & EMBR3 \\
GGBR4 & GOAU4 & ITSA4 & ITUB4 & KLBN4 & LIGT3 & LAME4 & OIBR4 & PCAR4 & PETR3 \\
PETR4 & SBSP3 & CSNA3 & CRUZ3 & VIVT4 & TIMP3 & TRPL4 & USIM5 & VALE3 & VALE5 \\
\hline
\end{tabular}

\section{A4 - ESTIMAÇÃO POR MÁXIMA VEROSSIMILHANÇA}

Avdis e Wachter (2014) derivam a forma fechada para estimar os parâmetros $\mu_{r}, \mu_{x}$, $\beta, \theta, \sigma_{u}^{2}, \sigma_{v}^{2}$ e $\sigma_{u v}$. Para isto, eles minimizam a função $L$ (que é o mesmo que maximizar o log da função de verossimilhança):

$$
\begin{gathered}
L\left(\beta, \theta, \mu_{r}, \mu_{x}, \sigma_{u v}, \sigma_{u}, \sigma_{v}\right)=\log \left(\sigma_{v}^{2}\right)-\log \left(1-\theta^{2}\right)+\frac{1-\theta^{2}}{\sigma_{v}^{2}}\left(x_{0}-\mu_{x}\right)^{2} \\
+T \log (|\Sigma|)+\frac{\sigma_{v}^{2}}{|\Sigma|} \sum_{t=1}^{T} u_{t}^{2}-2 \frac{\sigma_{u v}}{|\Sigma|} \sum_{t=1}^{T} u_{t} v_{t}+\frac{\sigma_{u}^{2}}{|\Sigma|} \sum_{t=1}^{T} v_{t}^{2}
\end{gathered}
$$

Não apresentaremos detalhadamente a álgebra que os autores fizeram para resolver as condições de primeira ordem derivadas da função acima. Entretanto, sinteticamente, o passo a passo para implementar a metodologia encontra-se a seguir.

Passo 1: Expressar $\hat{\mu}_{x}$ em termos de $\hat{\theta}$ e dos dados

$$
\hat{\mu}_{x}=\frac{(1+\hat{\theta}) x_{0}+\sum_{t=1}^{T}\left(x_{t}-\hat{\theta} x_{t-1}\right)}{(1+\hat{\theta})+(1-\hat{\theta}) T}
$$

Passo 2: Expressa a matriz de covariância em termos de $\hat{\mu}_{x}, \hat{\theta}, \hat{\mu}_{r}, \hat{\beta}$ e os dados

$$
\frac{\hat{\sigma}_{u v}}{\hat{\sigma}_{v}^{2}}=\frac{\sum_{t=1}^{T} \hat{u}_{t} \hat{v}_{t}}{\sum_{t=1}^{T} \hat{v}_{t}^{2}}
$$


Passo 3: Resolva $\hat{\theta}$ em termos dos dados. Isto também da $\hat{\mu}_{x}$ e $\hat{\sigma}_{v}^{2}$ em termos dos dados

$$
\begin{gathered}
0=T(\hat{\theta}-1)\left((T+1)\left(1-\hat{\theta}^{2}\right)+2 \hat{\theta}\right)\left(\sum_{t=0}^{T} x_{t}-\hat{\theta} \sum_{t=1}^{T-1} x_{t}\right)^{2} \\
+((T+1)-(T-1) \hat{\theta})(\hat{\theta}-1)\left(\sum_{t=0}^{T} x_{t}-\hat{\theta} \sum_{t=1}^{T-1} x_{t}\right) \\
x\left[2 T \hat{\theta}(1+\hat{\theta})\left(\sum_{t=1}^{T-1} x_{t}\right)-((T+1)+(T-1) \hat{\theta})\left(\sum_{t=0}^{T} x_{t}-\hat{\theta} \sum_{t=1}^{T-1} x_{t}\right)\right] \\
+((T+1)-(T-1) \hat{\theta})^{2} \\
x\left[\hat{\theta}\left(\left(1-\hat{\theta}^{2}\right) T+1\right)\left(\sum_{t=1}^{T-1} x_{t}^{2}\right)+\left(\hat{\theta}^{2}(T-1)-(T+1)\right) \sum_{t=1}^{T} x_{t} x_{t-1}+\hat{\theta} \sum_{t=0}^{T} x_{t}^{2}\right]
\end{gathered}
$$

Passo 4: Resolve $\hat{\mu}_{r}$ e $\hat{\beta}$ em termos dos dados. Isto também da a solução para $\hat{\sigma}_{u v} e$ $\hat{\sigma}_{u}^{2}$

$$
\begin{array}{r}
\hat{\mu}_{r}=\frac{1}{J}\left[\frac{1}{T} \sum_{t=1}^{T} r_{t}-\left(\frac{1}{T} \sum_{t=1}^{T} x_{t}-\hat{\mu}_{x}\right)\left(\frac{F-\beta^{O L S} H}{1+\left(\hat{\theta}-\theta^{O L S}\right) H}\right)\right. \\
\left.-\left(\frac{1}{T} \sum_{t=1}^{T} x_{t-1}-\hat{\mu}_{x}\right)\left(\frac{\left(\beta^{O L S}(1+\hat{\theta} H)-\theta^{O L S} F\right)}{(1+(\hat{\theta}-\theta \hat{O} L S) H)}\right)\right] \\
\hat{\beta}=\frac{\beta^{O L S}+\left(\hat{\theta}-\theta^{O L S}\right) F}{1+\left(\hat{\theta}-\theta^{O L S}\right) H}-\frac{\left(\hat{\theta}-\theta^{O L S}\right) G}{1+\left(\hat{\theta}-\theta^{O L S}\right) H} \hat{\mu}_{r} \\
\frac{\hat{\sigma}_{u v}}{\hat{\sigma}_{v}^{2}}=\frac{F-\beta^{O L S} H}{1+\left(\hat{\theta}-\theta^{O L S}\right) H}-\frac{G}{1+\left(\hat{\theta}-\theta^{O L S}\right) H} \hat{\mu}_{r}
\end{array}
$$


Onde:

$$
\begin{gathered}
J=1-\frac{G}{1+\left(\hat{\theta}-\theta^{O L S}\right) H}\left[\frac{1}{T} \sum_{t=1}^{T} x_{t}-\hat{\mu}_{x}-\theta^{O L S}\left(\frac{1}{T} \sum_{t=1}^{T} x_{t-1}-\hat{\mu}_{x}\right)\right] \\
F=\frac{\sum_{t=1}^{T} r_{t} \hat{v}_{t}}{\sum_{t=1}^{T} \hat{v}_{t}^{2}} \\
G=\frac{\sum_{t=1}^{T} \hat{v}_{t}}{\sum_{t=1}^{T} \hat{v}_{t}^{2}} \\
H=\frac{\sum_{t=1}^{T}\left(x_{t-1}-\hat{\mu}_{x}\right) \hat{v}_{t}}{\sum_{t=1}^{T} \hat{v}_{t}^{2}}
\end{gathered}
$$




\section{A5 - CONSTRUÇÃO DAS VARIAVEIS E MODELOS}

Tabela - Descrição das variáveis preditivas usadas

\begin{tabular}{|c|c|c|}
\hline Variável & Fonte/Frequência & Metodologia/Descrição \\
\hline Dividendo-Preço & $\begin{array}{l}\text { Economática } \\
\text { Mensal }\end{array}$ & $\begin{array}{l}\text { Representa os dividendos por ação pagos nos } \\
\text { últimos } 12 \text { meses divididos pelo preço corrente } \\
\text { excluído dividendos. Agregamos usando os } \\
\text { tickers elegíveis e ponderamos pelo valor de } \\
\text { mercado }\end{array}$ \\
\hline Dividend yield & $\begin{array}{l}\text { Economática } \\
\text { Mensal }\end{array}$ & $\begin{array}{l}\text { Representa os dividendos por ação pagos nos } \\
\text { últimos } 12 \text { meses divididos pelo preço inicial } \\
\text { excluído dividendo (12 meses anterior). } \\
\text { Agregamos usando os tickers elegíveis e } \\
\text { ponderamos pelo valor de mercado }\end{array}$ \\
\hline Lucro-preço & $\begin{array}{l}\text { Economática } \\
\text { Mensal }\end{array}$ & $\begin{array}{l}\text { Representa os lucros líquidos por ação pagos } \\
\text { nos últimos } 12 \text { meses divididos pelo preço } \\
\text { inicial excluído dividendo ( } 12 \text { meses anterior). } \\
\text { Agregamos usando os tickers elegíveis e } \\
\text { ponderamos pelo valor de mercado }\end{array}$ \\
\hline Payout & $\begin{array}{l}\text { Economática } \\
\text { Mensal }\end{array}$ & $\begin{array}{l}\text { Representa a razão entre os dividendos/ lucros } \\
\text { pagos nos últimos } 12 \text { meses. Chegamos nessa } \\
\text { variável dividendo a razão dividendo-preço pela } \\
\text { lucro-preço. }\end{array}$ \\
\hline ROE & $\begin{array}{l}\text { Economática } \\
\text { Mensal }\end{array}$ & $\begin{array}{l}\text { Representa a razão lucro líquido do exercício } \\
\text { dividido pelo patrimônio líquido inicial. } \\
\text { Excluímos as empresas que apresentaram } \\
\text { lucro líquido negativo }\end{array}$ \\
\hline Câmbio & $\begin{array}{l}\text { IPEA } \\
\text { Mensal }\end{array}$ & $\begin{array}{l}\text { Representa a taxa de câmbio comercial para } \\
\text { compra } R \$ / \text { S } \$\end{array}$ \\
\hline Selic & $\begin{array}{l}\text { IPEA } \\
\text { Mensal }\end{array}$ & Taxa de juros overnight - Selic \\
\hline IPCA & $\begin{array}{l}\text { IPEA } \\
\text { Mensal }\end{array}$ & Inflação - IPCA \\
\hline $\begin{array}{l}\text { Índice de } \\
\text { Expectativas (IEC) }\end{array}$ & $\begin{array}{l}\text { IPEA } \\
\text { Mensal }\end{array}$ & $\begin{array}{l}\text { Representa a taxa de variação do IEC. Este } \\
\text { indicador avalia o grau de confiança que a } \\
\text { população tem na situação geral do país e nas } \\
\text { condições presentes e futuras de sua família }\end{array}$ \\
\hline Swap - 180 dias & $\begin{array}{l}\text { IPEA } \\
\text { Mensal }\end{array}$ & $\begin{array}{l}\text { Taxa referencial de swaps - DI pré-fixada - } 180 \\
\text { dias - fim de período }\end{array}$ \\
\hline Swap - 360 dias & $\begin{array}{l}\text { IPEA } \\
\text { Mensal }\end{array}$ & $\begin{array}{l}\text { Taxa referencial de swaps - DI pré-fixada - } 360 \\
\text { dias - média do período }\end{array}$ \\
\hline $\begin{array}{l}\text { Volatilidade } \\
\text { Ibovespa }\end{array}$ & $\begin{array}{l}\text { IPEA } \\
\text { Diária }\end{array}$ & $\begin{array}{l}\text { Volatilidade do índice de ações: lbovespa - } \\
\text { fechamento. Calculada pelo Ipeadata com } \\
\text { base nas taxas diárias de retorno entre as } \\
\text { cotações de fechamento observadas nos } 21 \\
\text { últimos dias de negociação. Colocamos está } \\
\text { série numa frequência mensal. }\end{array}$ \\
\hline SMB & $\begin{array}{l}\text { Nefin } \\
\text { Diária }\end{array}$ & $\begin{array}{l}\text { O fator Small Minus Big (SMB) representa o } \\
\text { retorno do portfólio de ações com baixa } \\
\text { capitalização de mercado (small) menos o } \\
\text { retorno do portfolio formado por ações com alta } \\
\text { capitalização de mercado (big). Colocamos está } \\
\text { série numa frequência mensal. }\end{array}$ \\
\hline
\end{tabular}




\begin{tabular}{|c|c|c|}
\hline $\mathrm{HML}$ & $\begin{array}{l}\text { Nefin } \\
\text { Diária }\end{array}$ & $\begin{array}{l}\text { O fator High Minus Low (HML) representa o } \\
\text { retorno do portfólio de ações com alta razão } \\
\text { book-to-market menos o retorno do portfolio } \\
\text { formado por ações com baixa razão book-to- } \\
\text { market. Colocamos está série numa frequência } \\
\text { mensal. }\end{array}$ \\
\hline WML & $\begin{array}{l}\text { Nefin } \\
\text { Diária }\end{array}$ & $\begin{array}{l}\text { O fator Winners Minus Losers (WML) } \\
\text { representa o retorno do portfolio de ações com } \\
\text { altos retornos passados menos o retorno do } \\
\text { portfolio formado por ações que tiveram baixos } \\
\text { retornos passados. Colocamos está série numa } \\
\text { frequência mensal. }\end{array}$ \\
\hline IML & $\begin{array}{l}\text { Nefin } \\
\text { Diária }\end{array}$ & $\begin{array}{l}\text { O fator Illiquid Minus Liquid (IML) representa o } \\
\text { retorno do portfolio de ação liquidas menos o } \\
\text { retorno do portfolio de ações ilíquidas. } \\
\text { Colocamos está série numa frequência mensal. }\end{array}$ \\
\hline
\end{tabular}

\section{Modelo de Gordon Padrão}

Para testar o Modelo de Gordon Padrão, estimamos a série de prêmios gerados por esta abordagem para o período compreendido entre 1999:12 até 2014:12.

$$
\operatorname{Prêmio}_{t}=\frac{D_{t}}{P_{t}}\left(1+E_{t}\left(g_{t}^{D}\right)\right)+E_{t}\left(g_{t}^{D}\right)-r_{t}^{f}
$$

A razão dividendo-preço corresponde à série dos dividendos por ação pagos nos últimos 12 meses divididos pelo preço corrente excluídos dividendos. Calculamos a taxa de crescimento média dos dividendos $E_{t}\left(g_{t}^{D}\right)$ usando informações do inicio da amostra (1999:12) até o período $t$. Por fim, temos que $r_{t}^{f}$ representa a Selic.

\section{Modelo de Gordon padrão com recompras}

Acrescentamos ao Modelo de Gordon Padrão o valor das recompras $R_{t}$ :

$$
\text { Prêmio }_{t}=\left(\frac{D_{t}}{P_{t}}+\frac{R_{t}}{V M_{t}}\right)\left(1+E_{t}\left(g_{t}^{D}\right)\right)+E_{t}\left(g_{t}^{D}\right)-r_{t}^{f}
$$

Para chegar ao valor das recompras, calculamos a variação positiva na série fornecida pela Economática denominada quantidade de ações na tesouraria e, assim, obtemos a quantidade de ações recompradas. Em seguida, multiplicamos pelo preço corrente da ação e divididos pelo valor de mercado. 


\section{Modelo de dois estágios de crescimento}

O Modelo de Dois Estágios de Crescimento é semelhante ao de Gordon. Entretanto, usa a taxa de crescimento média do lucro líquido de curto e longo prazo. Calculamos a taxa de crescimento média do lucro liquido de curto prazo $E_{t}\left(g_{S R}\right)$ usando a media móvel dos lucros dos 5 meses prévios. Para a taxa de crescimento media de longo prazo $E_{t}\left(g_{L R}\right)$ usamos a informação disponível do inicio da amostra até $t$.

$$
\text { Prêmio }_{t}=\frac{D_{t}\left[1+E_{t}\left(g_{L R}\right)+5\left(E_{t}\left(g_{S R}\right)-E_{t}\left(g_{L R}\right)\right)\right]}{P_{t}}+E_{t}\left(g_{L R}\right)-r_{t}^{f}
$$

\section{Dividendos suavizados com EWMA}

Nesta abordagem, usamos a taxa de crescimento dos dividendos variando no tempo. Entretanto, suavizamos a série dando um peso de 0.25 para cada informação nova da taxa de crescimento.

$$
\operatorname{Prêmio}_{t}=\frac{D_{t}}{P_{t}}\left(1+g_{t}^{D}\right)+g_{t}^{D}-r_{t}^{f}
$$

\section{Dividendos estimados com AR(1)}

Usamos série da taxa de crescimento dos dividendos entre 1995m01 a 1999m11 para prever a taxa de crescimento entre $1999 \mathrm{~m} 12$ a 2014m12. A estimação foi realizada interativamente, ou seja, atualizando os parâmetros mês-a-mês. Para isto, usamos um modelo $\mathrm{AR}(1)$ com constante.

$$
g_{t}=\alpha+\beta g_{t-1}+e_{t}
$$

\section{Fama e French}

Pelos modelos dos dividendos e lucros de Fama e French (2002) temos:

$$
\begin{gathered}
\text { Prêmio }_{t}=E_{t}\left(\frac{D_{t}}{P_{t-1}}\right)+E_{t}\left(g_{t}^{D}\right)-E\left(r_{t}^{f}\right) \\
\text { Prêmio }_{t}=E_{t}\left(\frac{D_{t}}{P_{t-1}}\right)+E_{t}\left(g_{t}^{L}\right)-E\left(r_{t}^{f}\right)
\end{gathered}
$$


Onde $E_{t}\left(\frac{D_{t}}{P_{t-1}}\right), E\left(r_{t}^{f}\right), E_{t}\left(g_{t}^{D}\right)$ e $E_{t}\left(g_{t}^{L}\right)$ representa a média da série dividend yield, Selic, taxa de crescimento dos dividendos e lucros usando informação disponível do início da amostra até $t$, respectivamente.

A6 - VARIÁVEIS SELECIONADAS NA COMBINAÇÃO

\begin{tabular}{|c|c|c|c|c|}
\hline & $k=1$ & $k=12$ & $k=36$ & $k=60$ \\
\hline 2 & $\begin{array}{l}\text { Câmbio } \\
\text { Dividendo-preço }\end{array}$ & $\begin{array}{l}\text { Câmbio } \\
\text { Volatilidade Ibovespa }\end{array}$ & $\begin{array}{l}\text { Câmbio } \\
\text { Selic }\end{array}$ & $\begin{array}{l}\text { Swap - } 180 \text { dias } \\
\text { Selic }\end{array}$ \\
\hline 3 & $\begin{array}{l}\text { Câmbio } \\
\text { Dividendo-preço } \\
\text { Índice de Expectativas (IEC) }\end{array}$ & $\begin{array}{l}\text { Câmbio } \\
\text { Volatilidade Ibovespa } \\
\text { Dividendo-preço }\end{array}$ & $\begin{array}{l}\text { Câmbio } \\
\text { Selic } \\
\text { Swap - } 180 \text { dias }\end{array}$ & $\begin{array}{l}\text { Swap - } 180 \text { dias } \\
\text { Selic } \\
\text { Swap - } 360 \text { dias }\end{array}$ \\
\hline 4 & $\begin{array}{l}\text { Câmbio } \\
\text { Dividendo-preço } \\
\text { Índice de Expectativas (IEC) } \\
\text { Dividend yield }\end{array}$ & $\begin{array}{l}\text { Câmbio } \\
\text { Volatilidade Ibovespa } \\
\text { Dividendo-preço } \\
\text { Lucro - preço }\end{array}$ & $\begin{array}{l}\text { Câmbio } \\
\text { Selic } \\
\text { Swap - } 180 \text { dias } \\
\text { Média } 84 \text { meses }\end{array}$ & $\begin{array}{l}\text { Swap - } 180 \text { dias } \\
\text { Selic } \\
\text { Swap - } 360 \text { dias } \\
\text { Câmbio }\end{array}$ \\
\hline 5 & $\begin{array}{l}\text { Câmbio } \\
\text { Dividendo-preço } \\
\text { Índice de Expectativas (IEC) } \\
\text { Dividend yield } \\
\text { Lucro-preço }\end{array}$ & $\begin{array}{l}\text { Câmbio } \\
\text { Volatilidade Ibovespa } \\
\text { Dividendo-preço } \\
\text { Lucro - preço } \\
\text { Swap - } 360 \text { dias }\end{array}$ & $\begin{array}{l}\text { Câmbio } \\
\text { Selic } \\
\text { Swap - } 180 \text { dias } \\
\text { Média } 84 \text { meses } \\
\text { Swap - } 360 \text { dias }\end{array}$ & $\begin{array}{l}\text { Swap - } 180 \text { dias } \\
\text { Selic } \\
\text { Swap - } 360 \text { dias } \\
\text { Câmbio } \\
\text { Média } 84 \text { meses }\end{array}$ \\
\hline 6 & $\begin{array}{l}\text { Câmbio } \\
\text { Dividendo-preço } \\
\text { Índice de Expectativas (IEC) } \\
\text { Dividend yield } \\
\text { Lucro-preço } \\
\text { AR(1) }\end{array}$ & $\begin{array}{l}\text { Câmbio } \\
\text { Volatilidade lbovespa } \\
\text { Dividendo-preço } \\
\text { Lucro - preço } \\
\text { Swap - } 360 \text { dias } \\
\text { Swap - } 180 \text { dias }\end{array}$ & $\begin{array}{l}\text { Câmbio } \\
\text { Selic } \\
\text { Swap - } 180 \text { dias } \\
\text { Média } 84 \text { meses } \\
\text { Swap - } 360 \text { dias } \\
\text { Dividendo-preço }\end{array}$ & $\begin{array}{l}\text { Swap - } 180 \text { dias } \\
\text { Selic } \\
\text { Swap - } 360 \text { dias } \\
\text { Câmbio } \\
\text { Média } 84 \text { meses } \\
\text { Dividendo-preço }\end{array}$ \\
\hline 7 & $\begin{array}{l}\text { Câmbio } \\
\text { Dividendo-preço } \\
\text { Índice de Expectativas (IEC) } \\
\text { Dividend yield } \\
\text { Lucro-preço } \\
\text { AR(1) } \\
\text { Selic }\end{array}$ & $\begin{array}{l}\text { Câmbio } \\
\text { Volatilidade Ibovespa } \\
\text { Dividendo-preço } \\
\text { Lucro - preço } \\
\text { Swap - } 360 \text { dias } \\
\text { Swap - } 180 \text { dias } \\
\text { Selic }\end{array}$ & $\begin{array}{l}\text { Câmbio } \\
\text { Selic } \\
\text { Swap - } 180 \text { dias } \\
\text { Média } 84 \text { meses } \\
\text { Swap - } 360 \text { dias } \\
\text { Dividendo-preço } \\
\text { Dividend yield }\end{array}$ & $\begin{array}{l}\text { Swap - } 180 \text { dias } \\
\text { Selic } \\
\text { Swap - } 360 \text { dias } \\
\text { Câmbio } \\
\text { Média } 84 \text { meses } \\
\text { Dividendo-preço } \\
\text { Dividend yield }\end{array}$ \\
\hline
\end{tabular}

Nota: As linhas correspondem a quantidade de variáveis utilizadas e as colunas representam o horizonte do prêmio futuro. 